NBER WORKING PAPER SERIES

\title{
FISCAL REFORM AND GOVERNMENT DEBT IN JAPAN: \\ A NEOCLASSICAL PERSPECTIVE
}

\author{
Gary Hansen \\ Selo Imrohoroglu \\ Working Paper 19431 \\ http://www.nber.org/papers/w19431 \\ NATIONAL BUREAU OF ECONOMIC RESEARCH \\ 1050 Massachusetts Avenue \\ Cambridge, MA 02138 \\ September 2013
}

The authors thank Richard Rogerson, Nao Sudo and various seminar and conference participants for their comments and suggestions. In addition, we are grateful for invaluable support from the Institute for Monetary and Economic Studies, Bank of Japan, where we visited when beginning this project. The views expressed herein are those of the authors and do not necessarily reflect the views of the National Bureau of Economic Research.

NBER working papers are circulated for discussion and comment purposes. They have not been peerreviewed or been subject to the review by the NBER Board of Directors that accompanies official NBER publications.

(C) 2013 by Gary Hansen and Selo Imrohoroglu. All rights reserved. Short sections of text, not to exceed two paragraphs, may be quoted without explicit permission provided that full credit, including (C notice, is given to the source. 
Fiscal Reform and Government Debt in Japan: A Neoclassical Perspective

Gary Hansen and Selo Imrohoroglu

NBER Working Paper No. 19431

September 2013

JEL No. E2,E62,H6

\begin{abstract}
Past government spending in Japan is currently imposing a significant fiscal burden that is reflected in a net debt to output ratio near 150 percent. In addition, the aging of Japanese society implies that public expenditures and transfers payments relative to output are projected to continue to rise untillat least 2050. In this paper we use a standard growth model to measure the size of this burden in thelform of additional taxes required to finance these projected expenditures and to stabilize governmentldebt. The fiscal adjustment needed is very large, in the range of 30-40\% of total consumption expenditures. Using a distorting tax such as the consumption tax or the labor income tax requires either tax to rise to unprecedented highs, although the former is much less distorting than the latter. The extremely high tax rates we find highlight the importance of considering alternatives that attenuate the projected increases in public spending and/or enlarge the tax base.
\end{abstract}

Gary Hansen

UCLA

Department of Economics

8283 Bunche Hall

Box 951477

Los Angeles, CA 90095

and NBER

ghansen@econ.ucla.edu

Selo Imrohoroglu

Department of Finance and Business Economics

Marshall School of Business

University of Southern California

Los Angeles, CA 90089

selo@marshall.usc.edu 


\section{Introduction}

Due to large government stimulus in response to low economic growth in 1990s and 2000s, Japan accumulated the highest debt to output ratio among developed economies. In addition, this ratio is rising rapidly due to projected increases in public pensions and health expenditures. Figure 1 shows that net debt to Gross National Product (GNP) has risen from around 15\% of GNP in the early 1990s to about $110 \%$ in 2010, with further increases projected. ${ }^{1}$

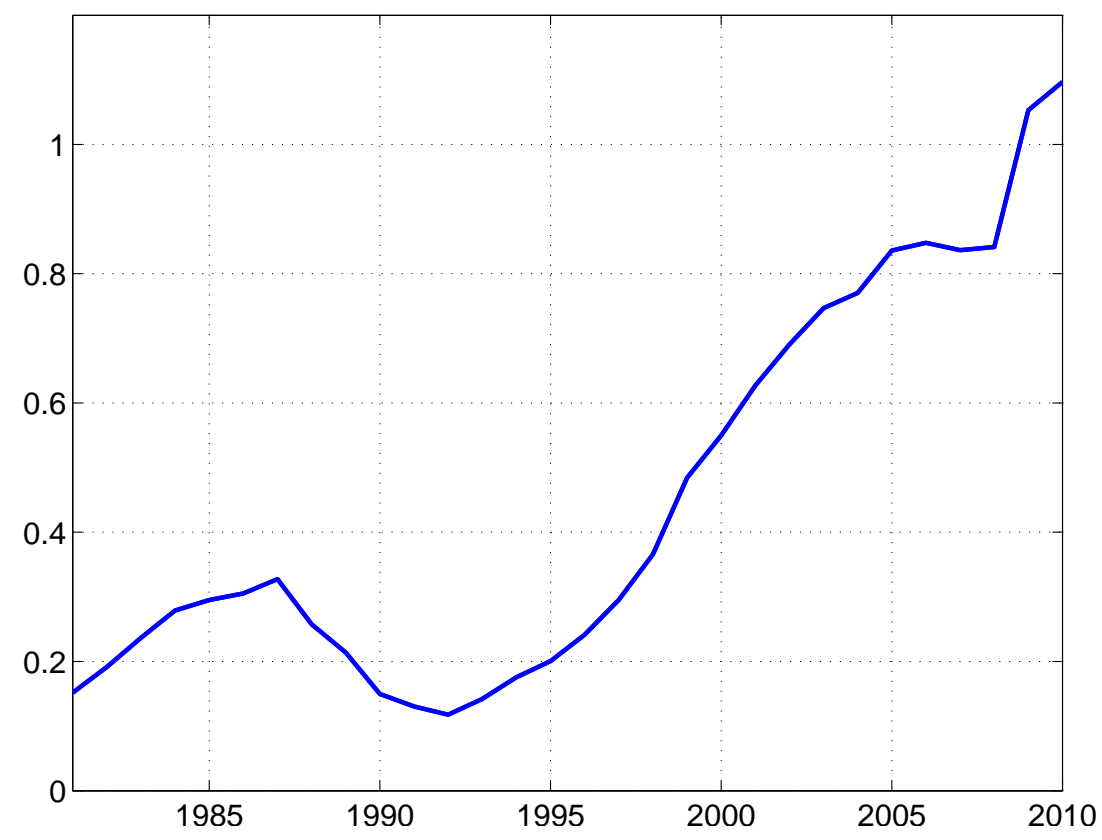

Figure 1: Net Debt to GNP Ratio

When compared with the experiences of other countries, it is surprising that Japan can have such a high debt to output ratio and yet pay very low interest rates on its debt. The majority of Japanese government debt, above 90\%, is held domestically and bond holders are presumably expecting sufficient future tax increases or spending cuts so that the government may be able to support high debt or ultimately reduce it to sustainable levels.

At the same time, Japan is facing a severe demographic transition that implies drastic increases in public pension payments and health expenditures in the future.

\footnotetext{
${ }^{1}$ Net debt is defined as the difference between financial liabilities and assets of the general government in Japanese national accounts. Our measure of GNP reflects adjustments to GNP from national accounts to be described in Section 3.
} 


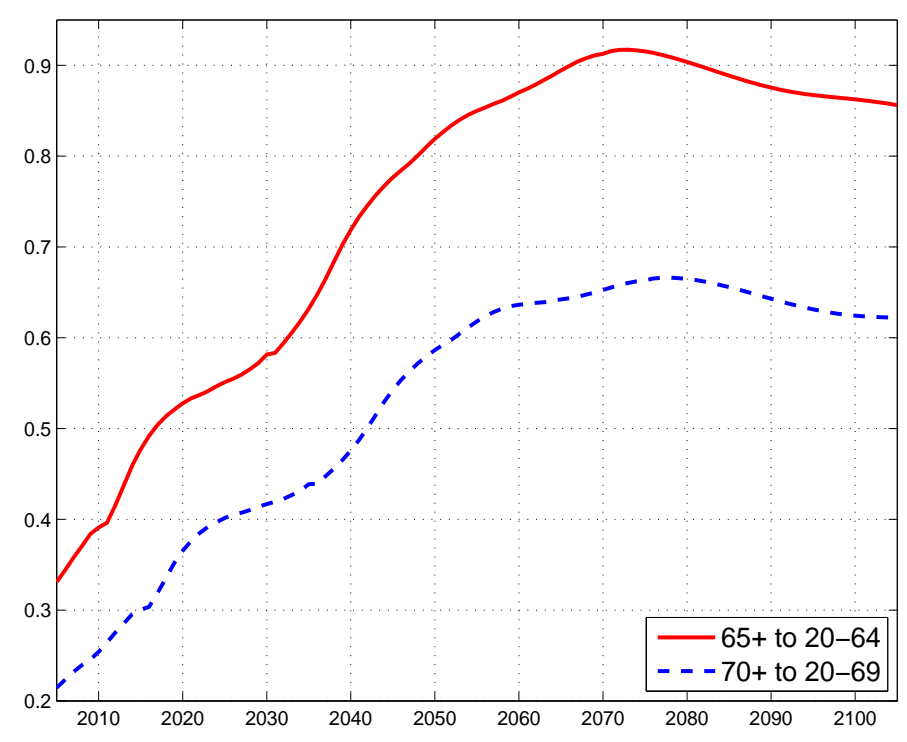

Figure 2: Dependency Ratios

Figure 2 above shows two dependency ratios; one shows the ratio of the number of 65 and older individuals to the number of 20 to 64 year old individuals, and a second one, the ratio of 70 and older individuals to the number of people between 20 and $69 .^{2}$ The second may be more relevant in the future as retirement ages are expected to increase. The first dependency ratio implies that about 3 workers are currently supporting 1 retiree. In about 60 years, this ratio is projected to increase to just over 1 worker paying taxes to support 1 retiree.

Clearly much additional revenue is required if benefits are to remain at current levels. Even when we consider a scenario where Japanese individuals work late into their $60 \mathrm{~s}$, the ratio of 70 and older individuals to the number of 20 to 69 year old workers is expected to increase from its current value of just over $20 \%$ to over $65 \%$ before stabilizing at $60 \%$ in the distant future. This is equivalent to having about 5 workers to support 1 retiree in 2005 but looking to have less than 2 workers to support a retiree in less than 40 years.

\footnotetext{
${ }^{2}$ The population data and projections are taken from the Population Statistics of Japan 2012, National Institute of Population and Social Security Research.
} 

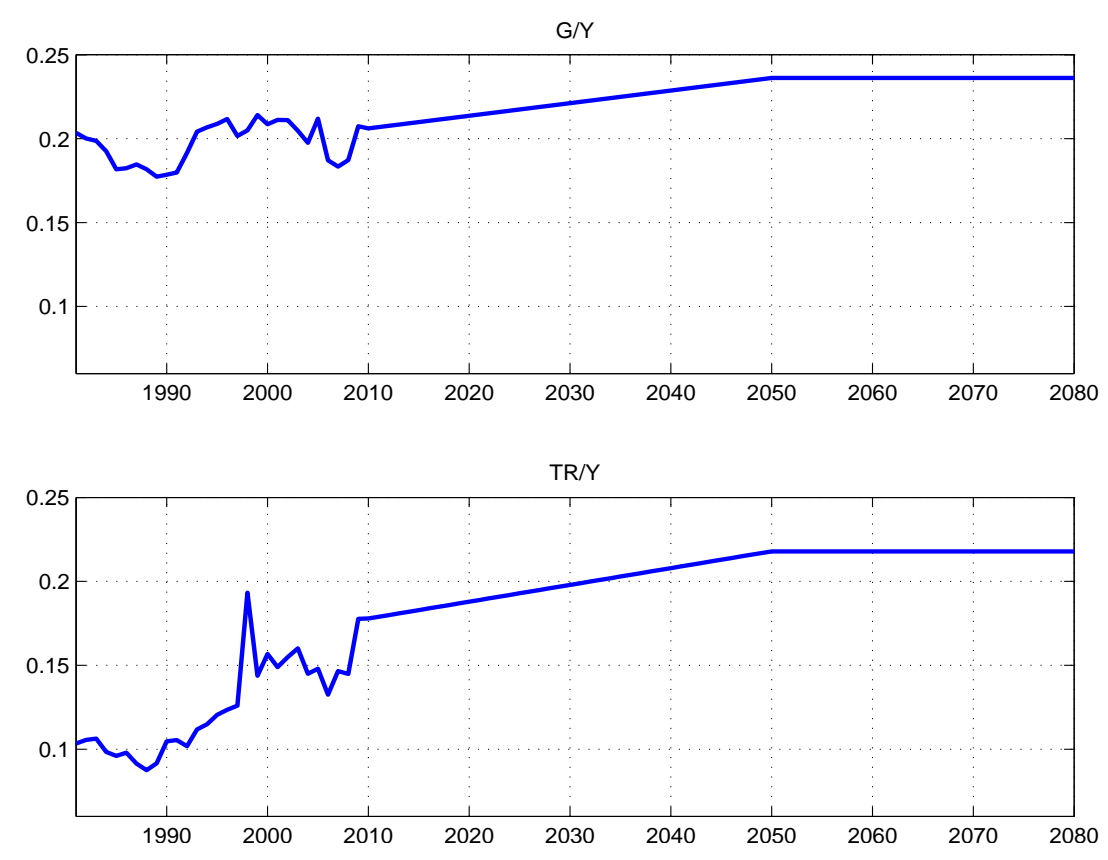

Figure 3: Government Expenditures to GNP Ratios

Figure 3 shows projections by Fukawa and Sato (2009) that imply large increases in government purchases to output driven by health expenditures and aging, and in transfer payments to output driven by expected increases in total pension payments. According to these projections, not only will there be far fewer workers paying taxes, but there will also be many more retirees requiring huge outlays for health expenditures and old age pensions. Assuming that it is not possible for the Japanese government to continue to issue additional debt to cover these expenditures, what sort of tax increases will be required for the Japanese fiscal policy to be sustainable?

In this paper, we develop a neoclassical growth model that builds on Hayashi and Prescott (2002) and Chen, İmrohoroğlu, and İmrohoroğlu (2006) by incorporating a strong domestic demand for government bonds and explore alternative ways of financing the projected increases in government expenditures. In particular, we ask "What are the revenue requirements and new taxes needed to finance future government expenditures and at the same time reduce the level of indebtedness to $60 \%$ of output in the long run?"

The model is a one sector deterministic growth model in which the private sector has perfect foresight about population growth rates, government policy and factor prices. Both the quantity and the price of bonds are endogenously determined in our model; government purchases of goods and services and transfer payments are exogenous. The government raises revenue by taxing factor incomes, interest income and consumption. The representative household values consumption, leisure, and government bonds and markets are complete. The inclusion of bonds in the utility function makes the model consistent with the very strong domestic demand for government bonds in Japan. ${ }^{3}$ A

\footnotetext{
${ }^{3}$ Sakuragawa and Hosono (2010) employ an alternative approach that incorporates intermediation costs to obtain low equilibrium interest rates on government debt.
} 
stand-in firm hires labor and rents capital from households.

After calibrating the model to the Japanese economy, we compute a transition path from given initial conditions in Japan in 1981 to a steady-state in the distant future. We incorporate forecasts of government purchases and transfer payments from Fukawa and Sato (2009) and projections of future population growth rates produced by the Japanese government. In our model, any debt to output ratio is sustainable in steady state as long as it is possible to raise sufficient tax revenue to cover expenditures as well as interest payments on the debt. ${ }^{4}$ Hence, we assume an arbitrary threshold debt to output ratio that, once reached, triggers tax increases that eventually bring this ratio down to a long run value of 60 percent. In our benchmark exercise, we compute the additional revenue, in the form of lump sum taxes or reductions in transfer payments, that must be raised in order to accomplish this transition. Next, we compute alternative transition paths in which the government increases distorting tax rates, either the consumption tax or labor income tax, and also consider the possibilities associated with increasing the tax base.

Our main finding is that the revenue required to finance the projected increases in government expenditures and to stabilize Japanese government debt is on the order of 30$40 \%$ of aggregate consumption per year. Furthermore, if the government uses distorting taxes such as the consumption tax, this tax rate must be increased to an unprecedented level of over $60 \%$. If the tax base is broadened, the consumption tax would still have to increase to approximately $40 \%$. The labor tax, however, is sufficiently distorting that it cannot be used by itself to accomplish the transition, even when tax broadening is implemented. Instead, the consumption tax must be increased along with the labor income tax rate. ${ }^{5}$

Given the unprecedented tax increases necessitated by this transition, increases that Japanese policymakers may want to avoid, our quantitative results motivate studying alternative reforms that would raise revenue and/or reduce government spending. Examples of such policies include reforms to the pension system (by reducing benefits or raising the retirement age), health insurance (increased premiums or co-pays), family policy (to raise fertility and female labor force participation), and allowing for increased immigration to Japan.

We are contributing to a large literature studying the additional revenue required to stabilize the debt to output ratio in Japan. A recent example is Doi, Hoshi, and Okimoto (2011) who estimate the tax revenue as a fraction of GDP required to sustain the debt at the 2010 level. They find that revenue has to go to 40-47\% of GDP (relative to $33 \%$ of GDP in 2010). They do not, however, consider what would be required if one were to use distorting taxes to raise this additional revenue. Hoshi and Ito (2012) find similar results.

Work that follows an approach similar to ours include İmrohoroğlu and Sudo (2011a) who also use the methodology of Hayashi and Prescott (2002). They measure the

\footnotetext{
${ }^{4}$ Hoshi and Ito (2012) endogenize the maximum debt to output ratio by assuming that government debt cannot exceed the total financial assets held by the private sector. This leads them to conclude that the maximum debt to output ratio is $246 \%$. We assume a maximum ratio of $250 \%$ in our benchmark case.

${ }^{5}$ Keen, Pradhan, Kang, and de Mooij (2011) also argue for increasing the consumption tax in Japan on the grounds that it is a less distorting way to raise the necessary revenue than the labor income tax.
} 
impact of raising the consumption tax rate in Japan from its current level of $5 \%$ to $15 \%$. They find that despite the temporary improvement in government revenues that produces primary surpluses for several years, eventually primary deficits re-emerge and the fiscal situation worsens. To see if a growth miracle may increase the tax base sufficiently to allow for fiscal balance, İmrohoroğlu and Sudo (2011b) try several scenarios under which exogenous growth in total factor productivity reduces the fiscal burden by lowering the projected increases in the government expenditures to output ratio on one hand and by raising the tax base on the other hand. They find that a decade of productivity growth of $6 \%$ or more is needed to restore fiscal balance in Japan, which is a growth experience that has not been achieved in any advanced economy over the last 35 years.

The paper is organized as follows. Section 2 describes the model economy and calibration is discussed in Section 3. Section 4 presents our quantitative results. Section 5 concludes.

\section{Model}

In this section we describe the details of our model. Upper case variables are per capita values that grow along a balanced growth path. Lower case variables are stationary along a balanced growth path.

The economy is populated by a representative household with $N_{t}$ members at time $t$. The size of the household is assumed to grow at a time-varying growth factor $\eta_{t}$ so that $N_{t+1}=\eta_{t} N_{t}$. There is no uncertainty in our economy; households are assumed to have perfect foresight.

The fiscal analysis in this paper takes as given time series on tax rates, government spending $\left(G_{t}\right)$, transfer payments $\left(T R_{t}\right)$, the working age population $\left(N_{t}\right)$, and total factor productivity $\left(A_{t}\right)$, where actual time series are used from 1981-2010. Forecasts and assumptions are used to extend these series to 2050 and beyond. In addition, we assume that the tax rates, the ratios of government purchases and transfer payments to output, and the growth rates of $N_{t}$ and $A_{t}$ are all eventually constant and the economy converges to a balanced growth path. A one sector neoclassical growth model is used to endogenously determine hours worked $\left(h_{t}\right)$, consumption $\left(C_{t}\right)$, output $\left(Y_{t}\right)$, the stock of capital $\left(K_{t}\right)$, tax revenues, government debt $\left(B_{t}\right)$, and the price of government bonds, $\left(q_{t}\right)$, from 1981 into the infinite future.

\subsection{Government}

We begin by describing the government's budget constraint. The government is assumed to collect revenue from taxing household consumption at the rate $\tau_{c, t}$, labor income at the rate $\tau_{h, t}$, capital income at the rate $\tau_{k, t}$, and interest on government bonds at the rate $\tau_{b, t}$. Given time series for $G_{t}$ and $T R_{t}$, the quantity of one-period discount bonds $\left(B_{t+1}\right)$ that are issued by the government is determined by the following budget constraint (where all quantities are in per capita terms): 


$$
\begin{aligned}
G_{t}+T R_{t}+B_{t}= & \eta_{t} q_{t} B_{t+1}+\tau_{c, t} C_{t}+\tau_{h, t} W_{t} h_{t} \\
& +\tau_{k, t}\left(r_{t}-\delta\right) K_{t}+\tau_{b, t}\left(1-q_{t-1}\right) B_{t}
\end{aligned}
$$

Here, in addition to variables already defined, $W_{t}$ and $r_{t}$ denote the wage rate and the return to capital, and $\delta$ is the depreciation rate of capital. In order to guarantee that the government obeys its intertemporal budget constraint, we assume a "debt sustainability" rule that forces the government to retire a fraction $\kappa$ of its debt that is in excess of what we assume the government will hold along its balanced growth path $\left(\bar{B}_{t}\right)$. In particular, we assume that the debt to output ratio along the balanced growth path is equal to $\bar{b}$.

This rule is triggered once the debt to output ratio exceeds some value $b_{\max }$.

$$
\iota_{t}= \begin{cases}1 & \text { if } B_{s} / Y_{s} \geq b_{\max } \text { for some } s \leq t \\ 0 & \text { otherwise }\end{cases}
$$

Once the sustainability rule is triggered, the government must generate revenue equal to $D_{t}$ that can be used to retire debt:

$$
D_{t}=\kappa \iota_{t}\left(B_{t}-\bar{B}_{t}\right)
$$

We will experiment with alternative ways to raise $D_{t}$ along the transition path to the balanced growth path. One way is to replace $T R_{t}$ with $T R_{t}^{*}=T R_{t}-D_{t}$. This is equivalent to $D_{t}$ being a lump sum tax and will serve as our benchmark case. Later, we will consider rules that replace $\tau_{c, t}$ and/or $\tau_{h, t}$ with larger tax rates that are sufficient to bring $B_{t} / Y_{t}$ to its steady state level $\bar{b}$.

\subsection{Household's Problem}

The household at time 0 is endowed with initial holdings of per capita physical capital $K_{0}>0$, and real, one-period, zero-coupon, discount bonds $B_{0}>0$. In addition, each member of the household is endowed with one unit of time each period that can be used for market activities $h_{t}$ or leisure $1-h_{t}$. Given a sequence of wages, rental rates for capital, government bond prices $\left\{W_{t}, r_{t}, q_{t}\right\}_{t=0}^{\infty}$, tax rates on consumption, and labor, capital and bond income, and per-capita transfer payments $\left\{\tau_{c, t}, \tau_{h, t}, \tau_{k, t}, \tau_{b, t}, T R_{t}\right\}_{t=0}^{\infty}$, the household chooses a sequence of per member consumption, hours worked, capital, and real bond holdings $\left\{C_{t}, h_{t}, K_{t+1}, B_{t+1}\right\}_{t=0}^{\infty}$ to solve the following problem:

$$
\max \sum_{t=0}^{\infty} \beta^{t} N_{t}\left[\log C_{t}-\alpha \frac{h_{t}^{1+1 / \psi}}{1+1 / \psi}+\phi \log \left(\mu_{t}+B_{t+1}\right)\right]
$$

subject to

$$
\begin{aligned}
\left(1+\tau_{c, t}\right) C_{t}+\eta_{t} K_{t+1}+q_{t} \eta_{t} B_{t+1}= & \left(1-\tau_{h, t}\right) W_{t} h_{t}+\left[\left(1+\left(1-\tau_{k, t}\right)\left(r_{t}-\delta\right)\right] K_{t}\right. \\
& +\left[1-\left(1-q_{t-1}\right) \tau_{b, t}\right] B_{t}+T R_{t}^{*},
\end{aligned}
$$


where $K_{0}>0$ and $B_{0}>0$ are given initial conditions. Here $K_{t+1}$ is per member holdings of capital at time $t+1$. $\eta_{t} K_{t+1}$ expresses the same quantity of capital per member at time $t$. The household's maximization is subject to a budget constraint where after-tax consumption expenditures and resources allocated to wealth accumulation in the form of capital and bond holdings are financed by after-tax labor income, after-tax capital income and holdings of capital, after-tax proceeds of bond holdings chosen in the previous period, and transfer payments from the government. The parameter $\beta$ denotes the household's subjective discount factor. The disutility of work is described by $-\alpha<0$ and $\phi>$ 0 denotes the household's preferences for government bonds. We use $\psi$ to denote the intertemporal elasticity of substitution (IES) of labor.

Since about $95 \%$ of the Japanese government bonds are held domestically, we assume that Japan is a closed economy where all debt is held by Japanese citizens, i.e. the Japanese household in our model. In addition, Japanese government bonds historically have had yields less than the return to physical capital. As a result, we introduce government debt in the utility function, with $\phi>0 .{ }^{6}$

Finally, $\mu_{t}$ is a parameter that limits the curvature of the period utility function over bonds. Essentially, it represents assets that might be perfect substitutes to Japanese government issued bonds in generating utility to households. ${ }^{7}$ We allow this parameter to move at the same rate of balanced growth as the rest of the economy so that the detrended version is a constant. In particular, $\mu_{t}=\mu A_{t}^{1 /(1-\theta)}$.

\subsection{Firm's Problem}

A stand-in firm operates a constant returns to scale Cobb-Douglas production technology

$$
\begin{aligned}
N_{t} Y_{t} & =A_{t}\left(N_{t} K_{t}\right)^{\theta}\left(N_{t} h_{t}\right)^{1-\theta} \\
N_{t+1} K_{t+1} & =(1-\delta) N_{t} K_{t}+N_{t} X_{t} .
\end{aligned}
$$

Capital depreciates at the rate $\delta$. The income share of capital is given by $\theta$. $A_{t}$ is total factor productivity which grows exogenously at the rate $\gamma_{t}$, so we have $A_{t+1}=\gamma_{t} A_{t}$. Per capita gross investment is denoted by $X_{t}$.

\subsection{Equilibrium}

Given a government fiscal policy $\left\{G_{t}, T R_{t}, D_{t}, B_{t}, \tau_{h, t}, \tau_{k, t}, \tau_{c, t}, \tau_{b, t}\right\}_{t=0}^{\infty}$, a debt sustainability rule $\left\{\kappa, \bar{b}, b_{\max }\right\}$, and the paths of working age population $\left\{N_{t}\right\}_{t=0}^{\infty}$ and technology $\left\{A_{t}\right\}_{t=0}^{\infty}$, a competitive equilibrium consists of an allocation $\left\{C_{t}, h_{t}, K_{t+1}, B_{t+1}\right\}_{t=0}^{\infty}$, factor prices $\left\{W_{t}, r_{t}\right\}_{t=0}^{\infty}$ and the bond price $\left\{q_{t}\right\}_{t=0}^{\infty}$ such that

\footnotetext{
${ }^{6}$ For example, consider a simplified version of the model in which the representative household solves $\max \sum_{t=0}^{\infty} \beta^{t}\left\{\log c_{t}+\phi \log b_{t+1}\right\}$ subject to $c_{t}+k_{t+1}+q_{t} b_{t+1}=w_{t}+r_{k, t} k_{t}+(1-\delta) k_{t}$. The first order conditions are given by $\frac{1}{c_{t}}=\beta \frac{R_{t}}{c_{t+1}}, \frac{\phi}{b_{t+1}}-\frac{q_{t}}{c_{t}}+\frac{\beta}{c_{t+1}}=0$, and $R_{t}=r_{t}+1-\delta$. Steady-state implies $q-\frac{1}{R}=\frac{\phi c}{b}>0$, which means that the return on $k$, denoted by $R$, dominates that on $b$ which is equal to $1 / q$.

${ }^{7}$ This parameter helps us to match the volatility of the bond prices.
} 
- the allocation solves the household's problem,

- the allocation solves the firm's profit maximization problem with factor prices given by: $W_{t}=(1-\theta) A_{t} K_{t}^{\theta} h_{t}^{-\theta}$, and $r_{t}=\theta A_{t} K_{t}^{\theta-1} h_{t}{ }^{1-\theta}$,

- the government budget is satisfied,

- the market for bonds clears,

- and the goods market clears: $C_{t}+\left[\eta_{t} K_{t+1}-(1-\delta) K_{t}\right]+G_{t}=Y_{t}$.

\subsection{Detrended Equilibrium Conditions}

In this subsection we derive the detrended equilibrium conditions to use in solving the model numerically. Given a trending per capita variable $Z_{t}$ we obtain its detrended per capita counterpart by

$$
z_{t}=\frac{Z_{t}}{A_{t}^{1 /(1-\theta)}}
$$

The first set of detrended equilibrium conditions is given below.

$$
\begin{aligned}
\frac{\left(1+\tau_{c, t+1}\right) \gamma_{t}^{1 /(1-\theta)} c_{t+1}}{\left(1+\tau_{c, t}\right) c_{t}} & =\beta\left[1+\left(1-\tau_{k, t+1}\right)\left(r_{t+1}-\delta\right)\right], \\
\frac{\phi}{\mu+b_{t+1}}+\frac{\beta \eta_{t}\left[1-\left(1-q_{t}\right) \tau_{b, t+1}\right]}{\left(1+\tau_{c, t+1}\right) c_{t+1}} & =\frac{q_{t} \eta_{t} \gamma_{t}^{1 /(1-\theta)}}{\left(1+\tau_{c, t}\right) c_{t}}, \\
\alpha h_{t}^{1 / \psi} & =\frac{\left(1-\tau_{h, t}\right) w_{t}}{\left(1+\tau_{c, t}\right) c_{t}}, \\
y_{t} & =k_{t}^{\theta} h_{t}^{1-\theta}, \\
\eta_{t} \gamma_{t}^{1 /(1-\theta)} k_{t+1} & =(1-\delta) k_{t}+x_{t} .
\end{aligned}
$$

Equation (4) is the typical Euler equation arising from the choice of capital stock at time $t$. The bond Euler equation is given by (5). The first order condition for hours worked is shown in equation (6). The production function and the law of motion for capital are given in equations (7) and (8), respectively. The budget constraint for the household is given below in equation (9)

$$
\begin{aligned}
& \left(1+\tau_{c, t}\right) c_{t}+\eta_{t} \gamma_{t}^{1 /(1-\theta)} k_{t+1}+q_{t} \eta_{t} \gamma_{t}^{1 /(1-\theta)} b_{t+1} \\
& \quad=\left(1-\tau_{h, t}\right) w_{t} h_{t}+\left[1-\left(1-q_{t-1}\right) \tau_{b, t}\right] b_{t}+t r_{t}-d_{t}+\left[1+\left(1-\tau_{k, t}\right)\left(r_{t}-\delta\right)\right] k_{t} .
\end{aligned}
$$

The government budget equation is given by equation (10)

$$
\begin{aligned}
g_{t}+t r_{t}+b_{t}= & q_{t} \eta_{t} \gamma_{t}^{1 /(1-\theta)} b_{t+1}+\tau_{c, t} c_{t}+\tau_{h, t} w_{t} h_{t} \\
& +\tau_{k, t}\left(r_{t}-\delta\right) k_{t}+\tau_{b, t}\left(1-q_{t}\right) b_{t}+d_{t} .
\end{aligned}
$$

Equation (11) is the detrended fiscal rule

$$
d_{t}=\kappa \iota_{t}\left(b_{t}-\bar{b} \bar{y}\right)
$$


where $\bar{y}$ is the value of $y_{t}$ along the balanced growth path. Recall that $\bar{b}$ is the targeted debt to output ratio along the balanced growth path and $\iota_{t}$ is an indicator function given by equation (2).

Finally, the market clearing conditions are given below in equations (12), (13) and

$$
\begin{aligned}
r_{t} & =\theta k_{t}^{\theta-1} h_{t}^{1-\theta}, \\
w_{t} & =(1-\theta) k_{t}^{\theta} h_{t}^{-\theta}, \\
c_{t}+x_{t}+g_{t} & =y_{t} .
\end{aligned}
$$

Hence we have 10 equations, (4) through (13), in 10 unknowns $\left\{c_{t}, x_{t}, h_{t}, y_{t}, k_{t+1}, b_{t+1}, d_{t}, q_{t}, w_{t}, r_{t}\right\}$ at each time period $t$.

\subsection{Solution Procedure}

Given a sequence $\left\{\tau_{c, t}, \tau_{h, t}, \tau_{b, t}, \tau_{k, t}, \eta_{t}, \gamma_{t}, g_{t}, t r_{t}\right\}_{t=1981}^{\infty}$, where these exogenous variables are constant beyond some date $T_{s}$ so that the endogenous variables that are determined by equations (4) through (13) converge to a steady state. Given a value for $c_{1981}$ we use these equations to calculate the sequence of endogenous variables

$\left\{c_{t}, x_{t}, h_{t}, y_{t}, k_{t+1}, b_{t+1}, d_{t}, q_{t}, w_{t}, r_{t}\right\}$ for all time periods. We use a shooting algorithm, similar to that in Hayashi and Prescott (2002) and Chen, Imrohoroğlu, and Imrohoroğlu (2006), to iterate on $c_{1981}$ which is equivalent to imposing a transversality condition on the capital stock. Note that our fiscal rule serves as a transversality condition on bond holdings.

\section{Calibration}

The structural parameters of our model are calibrated based on information from the sample period, which consists of annual data from 1981 to $2010 .^{8}$ We take the capitaloutput and bond-output ratios in 1981 as initial conditions and use the sample paths for total factor productivity (TFP), population growth rates, tax rates, government purchases and transfer payments as exogenous inputs to the model. In addition we make assumptions about the values for these exogenous variables beyond the sample period in order to calculate equilibrium transition paths from 1981 toward the eventual steady state.

Population: Our measure of population, $N_{t}$, is working age population between the ages of 20 and 69. We use the actual values between 1981 and 2010 and rely on official projections for 2011-2050. We assume that the population stabilizes after 2050; that is $\eta_{t}=1, t \geq 2050$. In section 4.4 we consider the effects of using total population as a measure of population instead of working age population.

\footnotetext{
${ }^{8}$ The main reason for taking the year 2010 as the last year for our sample is to abstract from the huge public expenditures in 2011 following the Great Tohoku Earthquake, tsunami and the nuclear disaster.
} 
National Accounts: Our measure of output is Gross National Product adjusted to include income from foreign capital, following Hayashi and Prescott (2002). In particular, we define the model's capital stock, $K_{t}$, as consisting of private fixed capital, held domestically and in foreign countries. We add net exports and net factor payments from abroad to measured private investment.

Government investment, including net land purchases, is assumed to be expensed. Therefore we treat it as part of government consumption and subtract depreciation of government capital from government consumption. We summarize these choices in Table 1 below:

Table 1: Adjustments to National Account Measurements

\begin{tabular}{lc}
\hline \hline$C=$ & Private Consumption Expenditures \\
$I=$ & Private Gross Investment \\
& $\quad+$ Change in Inventories \\
& $\quad+$ Net Exports \\
& $\quad+$ Net Factor Payments from Abroad \\
$G=\quad$ Government Final Consumption Expenditures \\
$\quad+$ General Government Gross Capital Formation \\
$\quad+$ Government Net Land Purchases \\
$\quad$ - Book Value Depreciation of Government Capital \\
\hline$Y=C+I+G$
\end{tabular}

Labor input: For $h_{t}$ we take the product of employment per working age population and average weekly hours worked, normalized by dividing by 98 , which is our assumption on discretionary hours available per week.

Government Accounts: Our measure of government purchases of goods and services, $G_{t}$, in Table 1, also includes Japanese public health expenditures. Transfer payments, $T R_{t}$, includes social benefits (other than those in kind, which are included in $G_{t}$ ) that are mostly public pensions, plus other current net transfers minus net indirect taxes. We also add $8 \%$ of output to our measure of transfers since our modeling of flat tax rates leads to higher tax revenue than in the data because we abstract from all deductions and exemptions that are present in the complicated Japanese tax code.

Tax Rates: Our measure of labor income tax rates, $\tau_{h, t}$, comes from the estimates of average marginal labor income tax rates by Gunji and Miyazaki (2011). The last value is 0.3324 for 2007 and we assume that this same value holds for 2008 and beyond in the benchmark calibration.

The capital income tax rate, $\tau_{k, t}$, is constructed following the methodology in Hayashi and Prescott (2002). The value of this tax rate for 2010 is 0.3557 . We assume that this value remains unchanged for 2011 and beyond. 
A consumption tax rate of $\tau_{c, t}=3 \%$ was introduced in Japan in 1989, and it was raised to $5 \%$ in 1997. This tax rate is scheduled to rise to $8 \%$ in 2014 and $10 \%$ in 2015 . In our benchmark calibration, we assume that the consumption tax rate stays constant at $10 \%$ beyond 2015 .

The tax rate on interest from government bonds, $\tau_{b, t}$, is equal to $20 \%$ for all time periods. This tax is imposed on the semiannual interest income from coupon-bearing bonds and is withheld ( $15 \%$ income tax plus $5 \%$ local tax) at the time the interest is paid.

Figure 4 below shows the tax rates used except for the tax on bond interest income, which is constant throughout at $20 \%$.

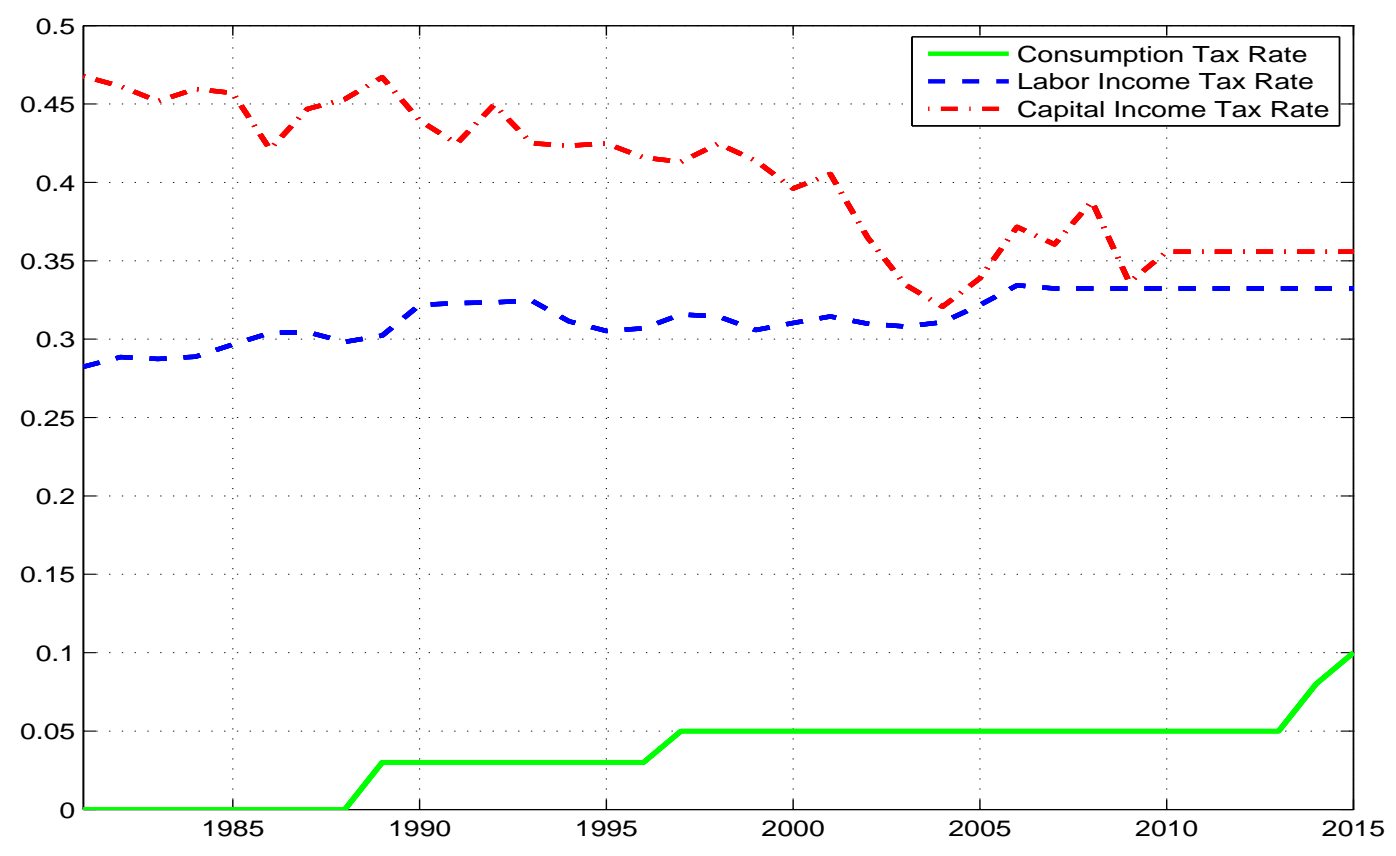

Figure 4: Tax Rates

Technology parameters: Given the data described above, the Cobb-Douglas production function allows us to calculate total factor productivity:

$$
A_{t}=Y_{t} /\left(K_{t}^{\theta} h_{t}^{1-\theta}\right)
$$

The capital income share, $\theta$, is set equal to 0.3783 , which is the sample (1981-2010) average of the annual ratio of capital income to our adjusted measure of GNP.

The measure of the growth factor of TFP, $\gamma_{t}=A_{t+1} / A_{t}$, comes from the actual data between 1981 and 2010. For 2011 and beyond, we assume that $\gamma_{t}=1.015^{1-\theta}$. This implies a growth rate of $1.5 \%$ for per capita output along the balanced growth path.

Our estimate for $\delta=0.0842$ comes from the sample average, following Hayashi and Prescott (2002). Table 2 summarizes these choices. 
Table 2: Calibration of TFP and Population Growth Rates

\begin{tabular}{llll}
\hline \hline & $1981-2010$ & $2011-2050$ & $2051-\infty$ \\
$\gamma_{t}$ & Actual Values & $1.015^{(1-\theta)}$ & $1.015^{(1-\theta)}$ \\
$\eta_{t}$ & Actual Values & Government Projections & 1.0 \\
\hline \hline
\end{tabular}

We show the demographic, technological and fiscal inputs that are exogenous to the model in Figure 5. The projected fiscal burden due to the aging of the Japanese population is reflected in the projected increases in government purchases and transfer payments. Taking these demographic, technological and expenditure variables as given, and assuming a target of an eventual 60\% debt to GNP ratio in the steady state, we compute the magnitude of the fiscal adjustment necessary to achieve fiscal balance in Japan.
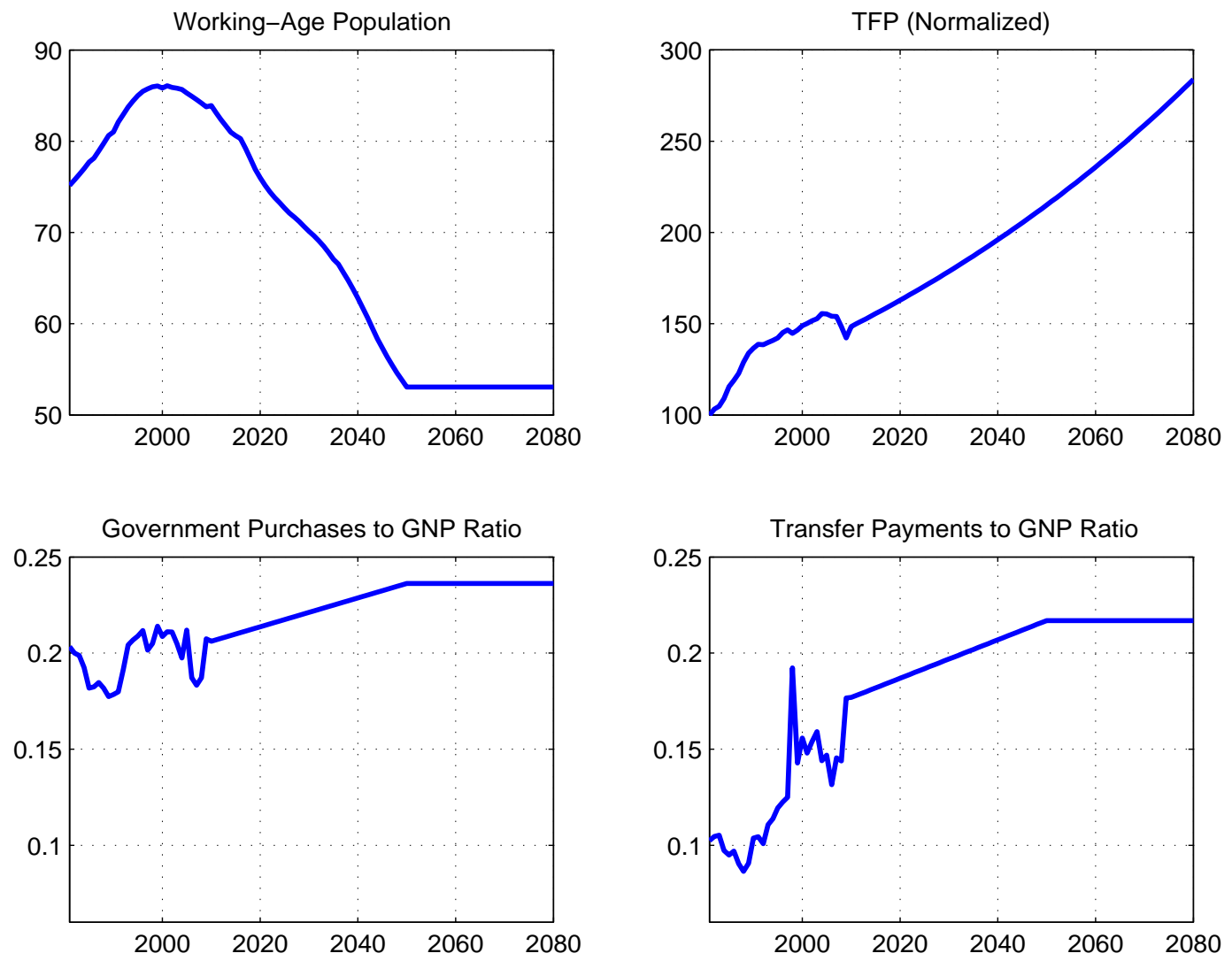

Figure 5: Model Inputs

Preference parameters: There are five preference parameters, $\beta, \alpha, \psi, \phi$, and $\mu$, in the utility function given by equation (3), where $\mu=\mu_{t} / A_{t}^{1 /(1-\theta)}$. These are held constant 
throughout our analysis. The parameter $\psi$ is the Frisch elasticity of labor supply, taken as 0.5, following Chetty, Guren, Manoli, and Broda (2012).

For the three preference parameters $\beta, \alpha$, and $\phi$, we use the equilibrium conditions given in equations (15), (16), and (17) for the sample period to obtain values for each year, and then averages over the sample.

$$
\begin{aligned}
\beta_{t} & =\frac{\left(1+\tau_{c, t+1}\right) \gamma_{t}^{1 /(1-\theta)} c_{t+1}}{\left(1+\tau_{c, t}\right) c_{t}\left[1+\left(1-\tau_{k, t+1}\right)\left(\theta \frac{y t+1}{k_{t+1}}-\delta\right)\right]} \\
\alpha_{t} & =\frac{h_{t}^{-1 / \psi}\left(1-\tau_{h, t}\right)(1-\theta) y_{t}}{\left(1+\tau_{c, t}\right) c_{t} h_{t}} \\
\phi_{t} & =\eta_{t}\left(\mu+b_{t+1}\right)\left[\frac{q_{t} \gamma_{t}^{1 /(1-\theta)}}{\left(1+\tau_{c, t}\right) c_{t}}-\frac{\beta_{t}\left[1-\left(1-q_{t}\right) \tau_{b, t+1}\right]}{\left(1+\tau_{c, t+1}\right) c_{t+1}}\right] .
\end{aligned}
$$

Note, however, that the equilibrium condition in equation (17) contains the equilibrium price of government bonds, $q_{t}$. The empirical counterpart to $q_{t}$ that we compute reflects the fact that government debt in actual economies is comprised of bond holdings of varying maturities while our model economy includes only one period discount bonds. In particular, let $B_{t}$ be beginning of period debt and $P_{t}$ be interest payments made in period $t$, both measured in current Yen. In addition, let $F_{t}$ be the GNP deflator. We compute the price of bonds in period $t$ as follows:

$$
q_{t}=\frac{B_{t+1} / F_{t}}{\left(B_{t+1}+P_{t+1}\right) / F_{t+1}} .
$$

Using data on $B_{t+1}, F_{t}$, and $P_{t+1}$ over the sample period, we compute $q_{t}$ and feed the values into the equilibrium conditions above to calculate the sample values of the preference parameters.

Figure 6 shows the sequences of $\left\{q_{t}\right\}_{1981}^{2009}$ calculated from the data using equation 18 and that implied by our benchmark calibration. In addition, we show the same sequence when $\phi=0$ and bonds earn the same rate of return as capital. With $\phi>0$, households are willing to hold government debt at a higher bond price and lower return than in the $\phi=0$ case. 


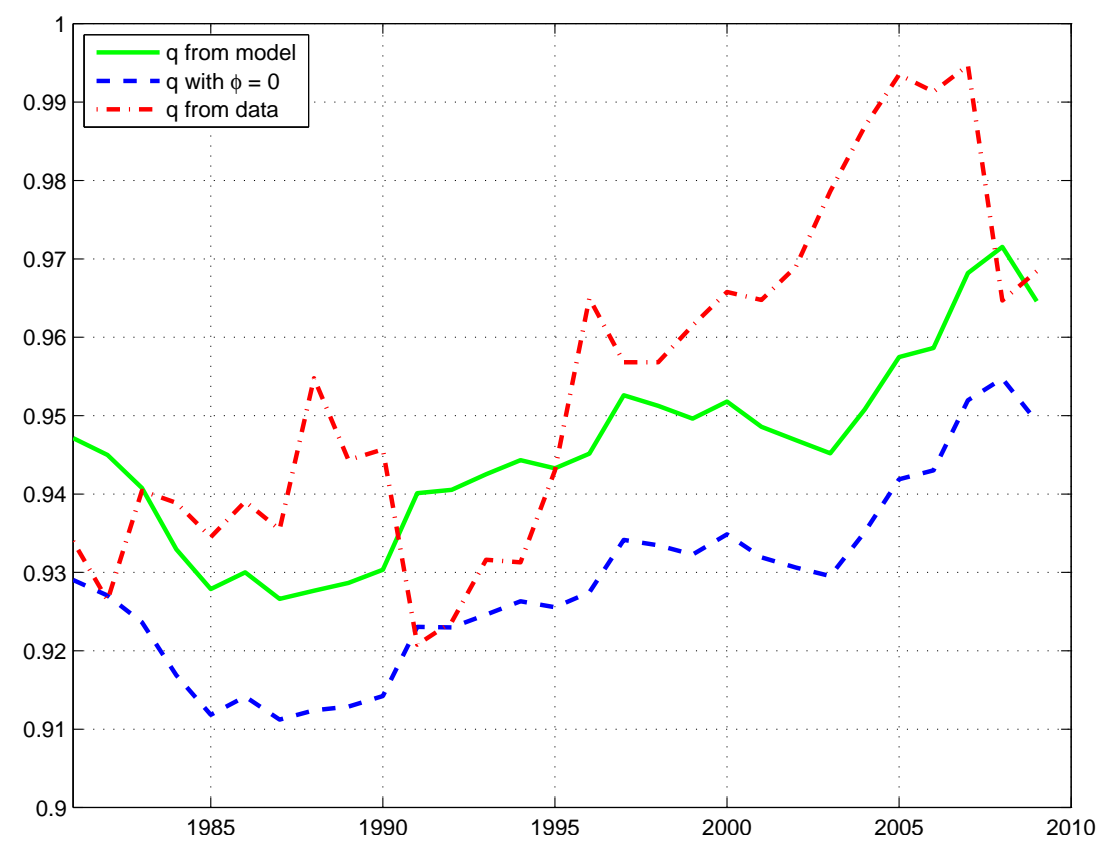

Figure 6: Bond Prices

In Figure 7, we compare the rates of return on capital and bonds in our model, both before and after tax. The rate of return dominance of capital over bonds is apparent in this figure.
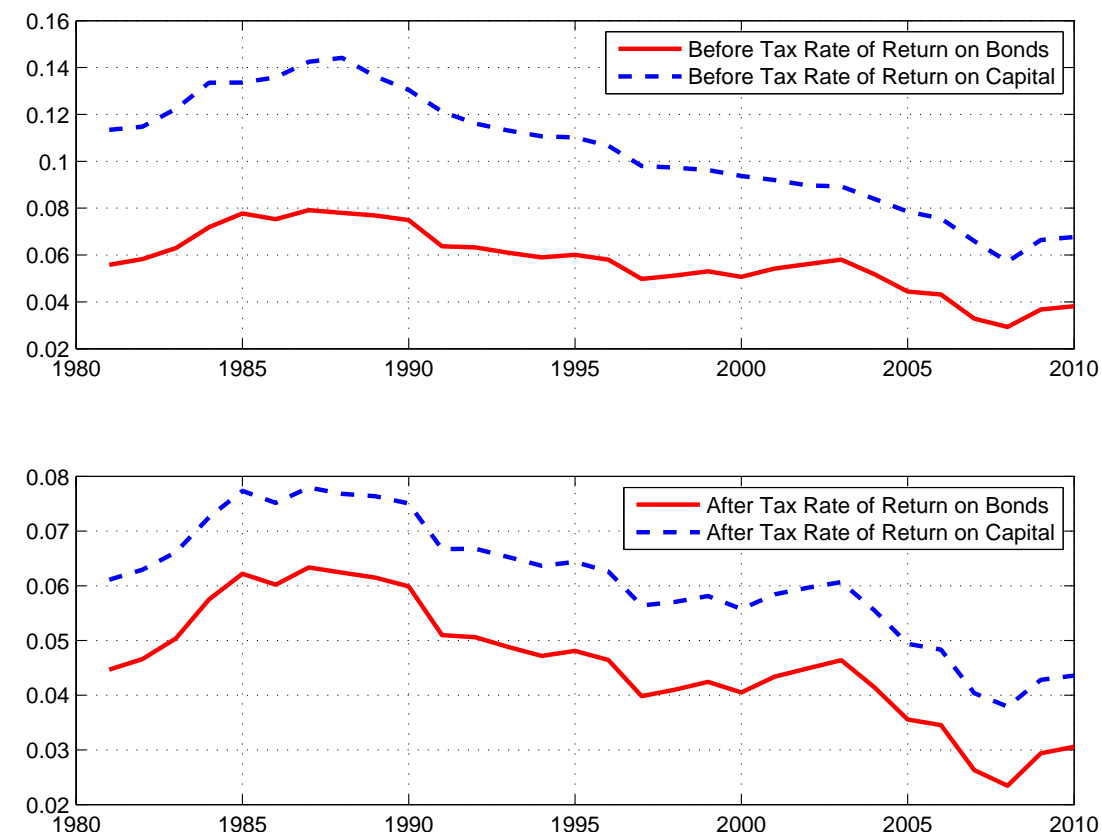

Figure 7: Returns on Capital and Bonds

The remaining preference parameter $\mu$, which is the detrended value of $\mu_{t}$, is chosen 
to minimize the sum of squared differences between the bond price implied by our model and its data counterpart.

Table 3 reports the values for the structural parameters.

Table 3: Calibration of Structural Parameters

\begin{tabular}{lll}
\hline \hline Parameter & Value & \\
\hline$\theta$ & 0.3783 & Data Average \\
\hline$\delta$ & 0.0842 & Data Average \\
\hline$\beta$ & 0.9677 & FOC, 1981-2010 \\
\hline$\alpha$ & 22.6331 & FOC, 1981-2010 \\
\hline$\psi$ & 0.5 & Chetty et al $(2012)$ \\
\hline$\phi$ & 0.063 & FOC, 1981-2010 \\
\hline$\mu$ & 1.1 & fit $q_{t}$ for $1981-2010$ \\
\hline \hline
\end{tabular}

\section{Quantitative Experiments}

As we mentioned in the Introduction, Japan's already high debt to output ratio is projected to rise even further due to the aging of the population. Fukawa and Sato (2009) estimate an increase of 3 percentage points in the ratio of government purchases to output and a 4 percentage point rise in transfer payments to output from 2010 to $2050 .{ }^{9}$ These estimates are very similar to those calculated independently by Imrohoroğlu, Kitao, and Yamada (2013). This growth in debt may not be sustainable and requires a fiscal rule that guarantees that the government's intertemporal budget is satisfied.

\subsection{Benchmark Experiment}

In our benchmark exercise, the government imposes lump sum taxes (or, equivalently, reduces transfers) when the bond to output ratio reaches some critical value. Later, we will consider alternative fiscal policies that impose distorting taxes and/or broadening the tax base to retire debt. In what follows, we describe how we implement the fiscal sustainability rule introduced earlier in equation (11).

\subsubsection{Fiscal Sustainability Rule}

We repeat below the equations that describe the benchmark fiscal rule.

\footnotetext{
${ }^{9}$ The projections in Fukawa and Sato (2009) are based on the financial projections produced in Sato and Kato (2007). These projections come from a system of equations that form their accounting model. Some of the equations, such as the consumption of fixed capital, production function, pension benefits, medical expenditures, etc., are estimated from Japanese data, using age brackets when appropriate. Other inputs to the equations are taken from population projections and government's long-term care expenditure estimates. For mortality projections, the medium variant is used. The rate of growth of real GDP is assumed to be $2 \%$. The income share of labor is estimated to be $57 \%$.
} 


$$
\begin{aligned}
d_{t} & =\kappa \iota_{t}\left(b_{t}-\bar{b} \bar{y}\right) \\
\iota_{t} & = \begin{cases}1 & \text { if } B_{s} / Y_{s} \geq b_{\max } \text { for some } s \leq t, \\
0 & \text { otherwise }\end{cases}
\end{aligned}
$$

Values need to be assigned to the three parameters, $\kappa, b_{\max }$, and $\bar{b}$, that characterize this policy. For $b_{\max }$, the maximum net debt to output ratio beyond which fiscal austerity kicks in, we try three values, 200\%, 250\%, and 300\%. For most countries, these values may seem too high. For Japan, however, these may be more reasonable. Indeed, the (net) debt to output ratio for 2013 is around $150 \%$. As we argue below, our choice of $b_{\max }$ is $250 \%$, which is very close to the maximum sustainable debt to output ratio estimated by Hoshi and Ito (2012).

For the debt to output ratio along the balanced growth path, $\bar{b}$, we use a value of $60 \%$. This is loosely motivated by the debt to output ratio that was once viewed as an upper bound for European Union member countries that are also a part of European Monetary Union before the recent Euro debt problems. ${ }^{10}$

Figure 8 illustrates how we choose $\kappa$ for the benchmark value of $b_{\max }=250 \%$. The upper panel of this figures shows the paths implied by our model for the debt to output ratios under three possible values for $\kappa$. The endogenous date at which our sustainability rule is triggerred is 2021, at which time the government begins to retire a fraction $\kappa$ of the debt in excess of the steady-state value, $\bar{b} \bar{y}$. A value of $\kappa, 0.05$, as can be seen in Figure 8 is insufficient to rein in the debt to output ratio which continues to grow beyond 2021. The two larger values shown, 0.1 and 0.15 , do succeed in bringing the debt to output ratio under control.

The lower panel of Figure 8 quantifies $d_{t} / c_{t}$, which is the revenue required to retire debt as a fraction of consumption expenditures, for different values of $\kappa$. We refer to this as the "consumption tax equivalent revenue requirement."

We choose the smallest value of $\kappa$ that is sufficient to cause the debt to output ratio to fall once the trigger is activated. A value of $\kappa=0.15$ would allow the debt to output ratio to fall more quickly, but, as can be seen from the bottom panel of Figure 8 , this value would involve collecting more revenue than necessary in the initial periods after the trigger is activated. But $\kappa=0.1$ works to achieve our targeted fiscal balance.

\footnotetext{
${ }^{10}$ We experimented with higher steady-state debt to output ratios, such as $100 \%$. This higher value had very little quantitative impact on the fiscal burden along the transition.
} 

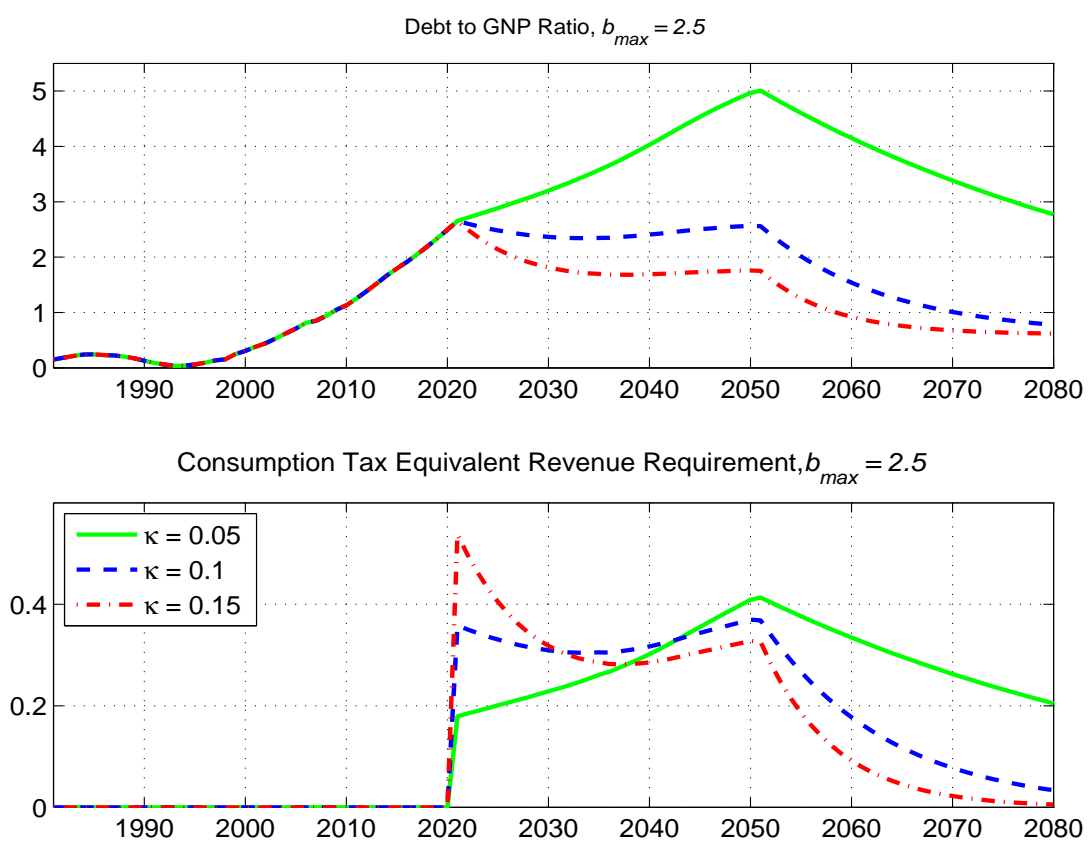

Figure 8: Revenue Requirement in the Benchmark Economy

Note that as long as debt exceeds the steady-state value, $\iota_{t}$ is equal to 1 and debt is brought down by lump sum taxes (equivalent to a reduction in transfers). As the difference between actual debt and its steady-state value becomes small, the revenue requirement gets smaller and eventually, when the government purchases to output and transfer payments to output become stationary in 2050, the need to levy lump sum taxes to bring debt to a sustainable steady state level vanishes.

Figures (9) and (10) illustrate the paths of the bond to output ratios and the revenue requirements for the two alternative values for $b_{\max }$. For $b_{\max }=200 \%$ and $b_{\max }=$ $300 \%$, we choose $\kappa=0.12$ and $\kappa=0.085$, respectively, for the same reason outlined above. 


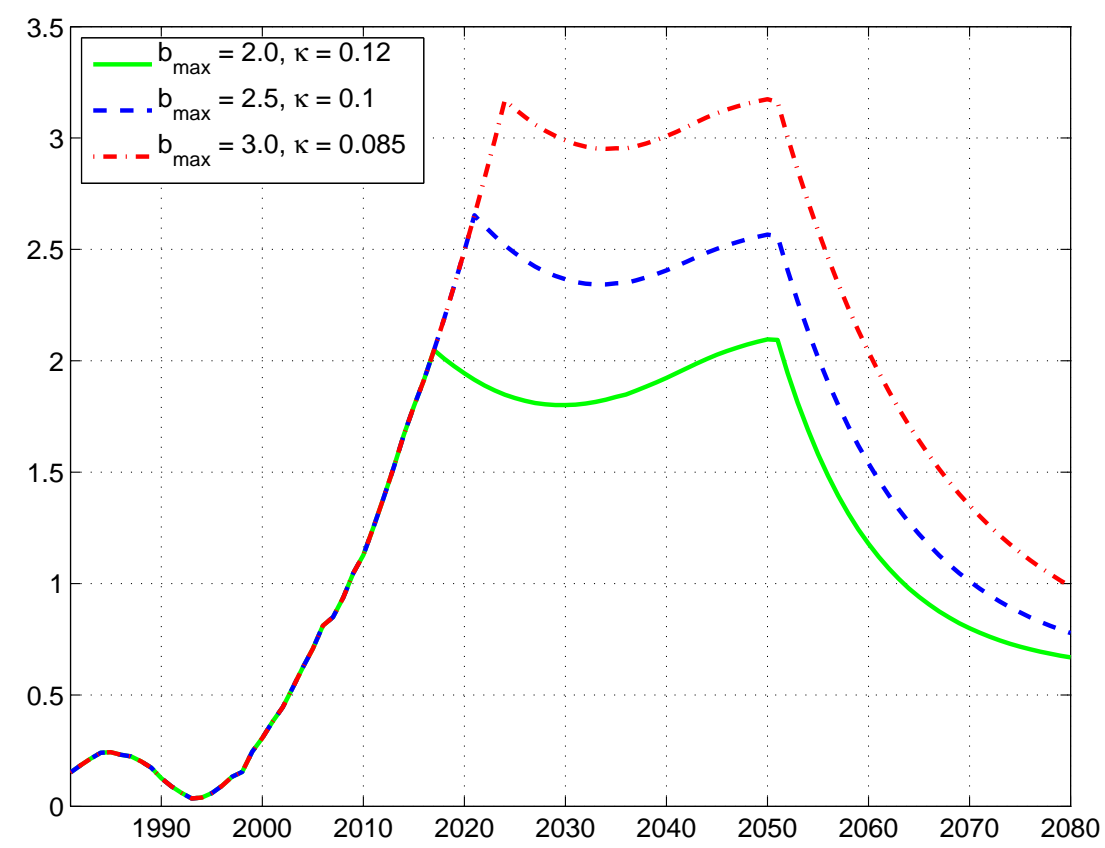

Figure 9: Alternative Times Paths for Debt to Output Ratio

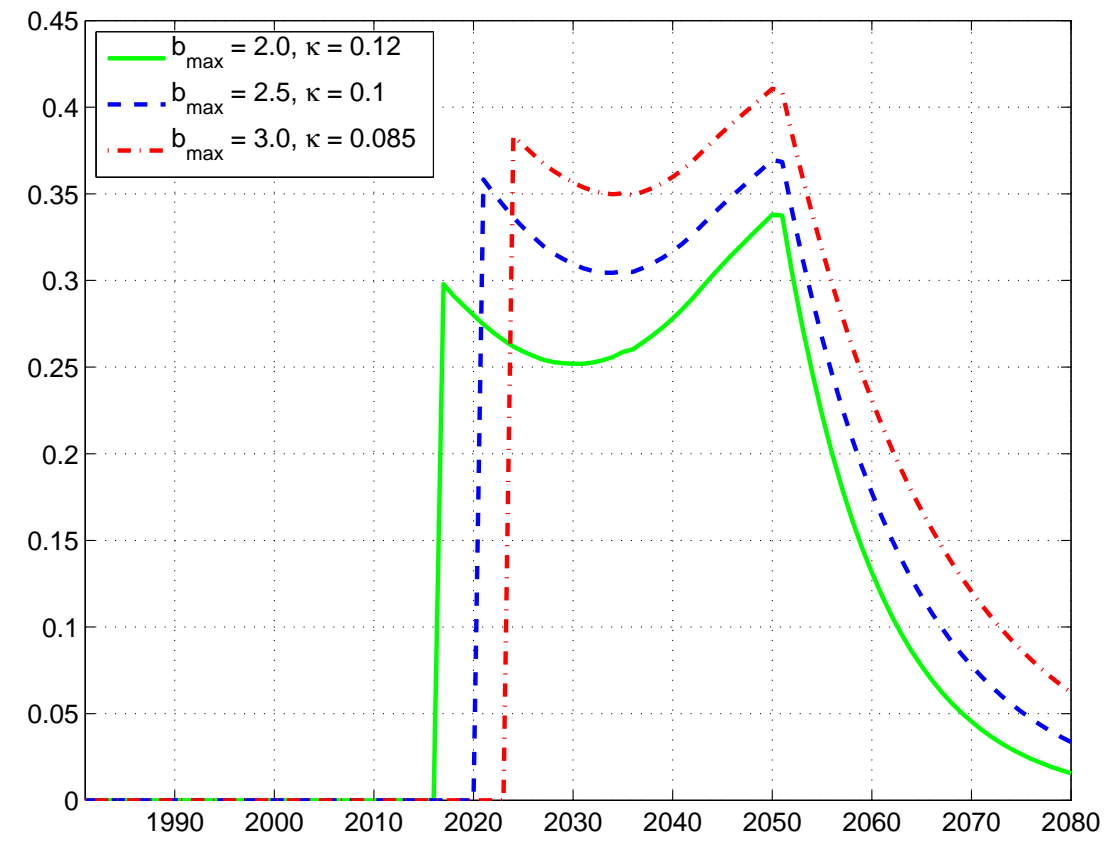

Figure 10: Revenue Requirement as Fraction of Aggregate Consumption 


\subsubsection{Comparison with Japanese Data}

Although our primary interest is in projecting the path for endogenous variables beyond our sample period, we first report the time paths over the sample period 1981-2010 generated by our calibrated model and their counterparts from Japanese data. This allows us to evaluate similarities and differences between actual data and those generated by the model.

Figure 11 shows data and model comparisons for hours worked, capital stock and output. The last two variables are normalized so that 1981 values equal 100 .
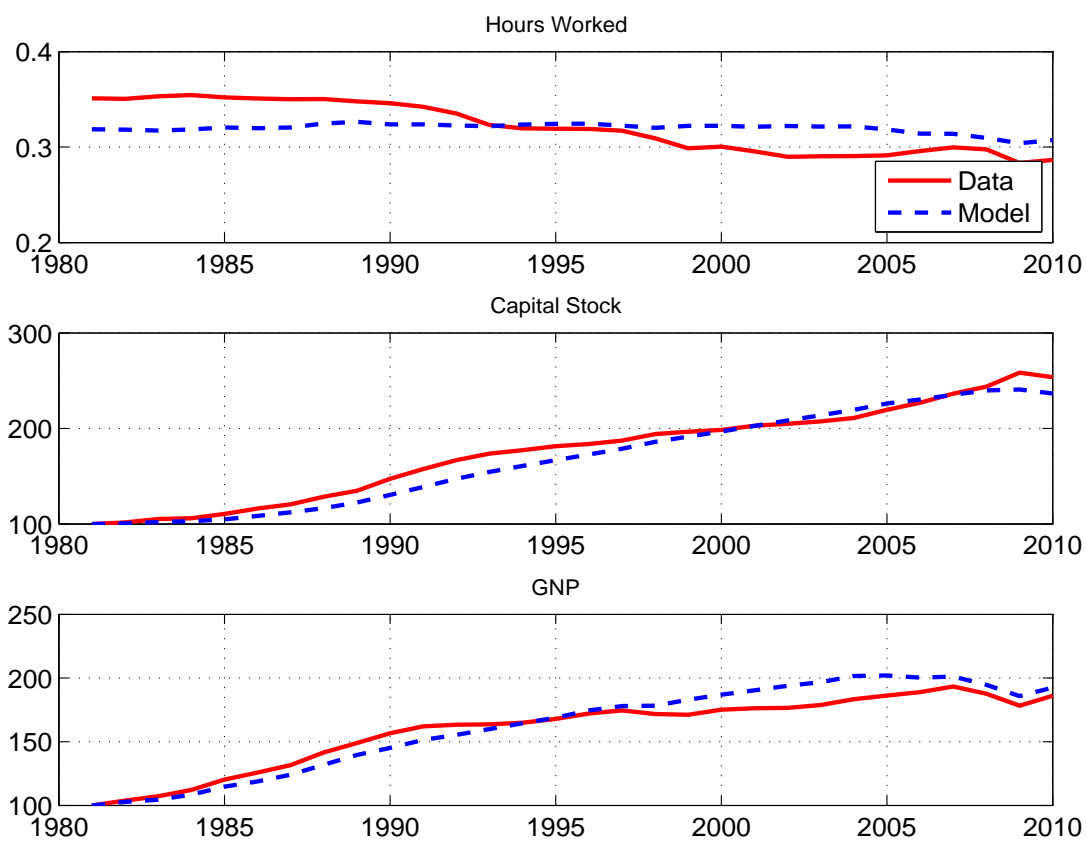

Figure 11: Labor, Capital, and Output

A striking aspect of Figure 11 is that our model does not quite match the observed time path for hours worked. During the 1990's, labor supply fell significantly in Japan. Hayashi and Prescott (2002) attribute some of this decline to the legislated reduction in the length of the work week in Japan, a feature that is absent in our model. As a result, the model predicts a flatter hours path than observed in the data.

Figure 12 illustrates data and model consumption and investment, normalized to equal 100 in 1981, and the capital-output ratio. Here, one can see that the model predicts higher investment during the 1990's and early 2000's than actually observed. This may be due to the substitution toward capital goods with lower depreciation rates during this period, something that is not featured in our model. ${ }^{11}$ Toward the end of the 1981-2010 period, there is more agreement between the model and the data.

\footnotetext{
${ }^{11}$ Using the methodology for computing the depreciation rate in Hayashi and Prescott (2002), we find that the rate of depreciation fell from $9.1 \%$ in 1989 to $7.5 \%$ in 2010 .
} 

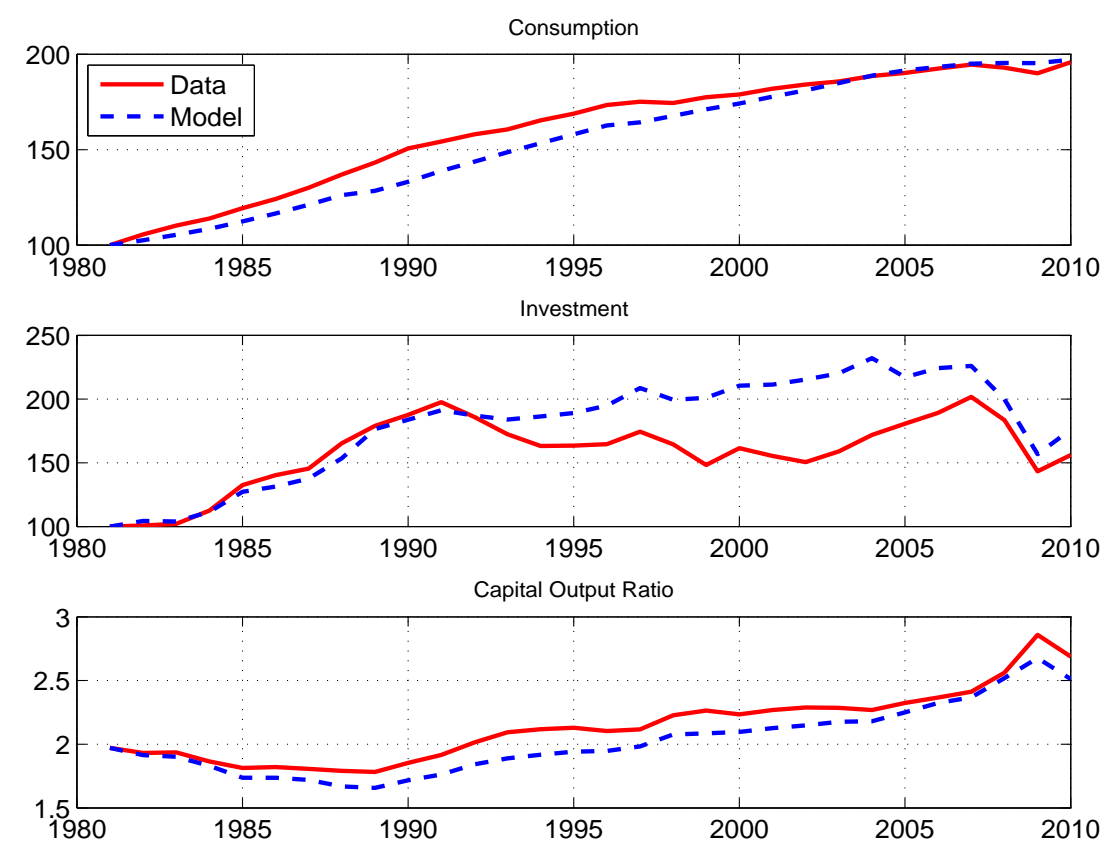

Figure 12: Consumption, Investment, and Capital-Output Ratio

Figure 13 shows the debt to output ratio from the Japanese data and that generated by our model. Recall that we add $8 \%$ of output to our measure of transfers to account for the fact that our model abstracts from exemptions and reductions in the Japanese tax code. With this assumption, our endogenous debt to output ratio is very much in line with that in the data.

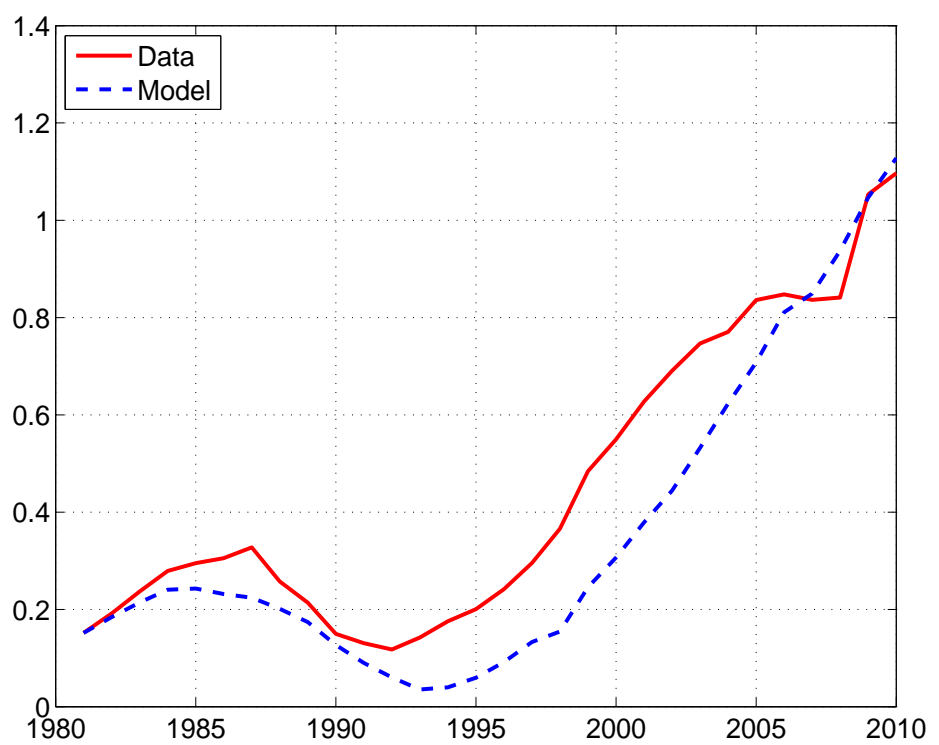

Figure 13: Net Debt to GNP Ratio 


\subsection{Steady State Analysis}

Our benchmark experiment relies on lump-sum taxes and transfers to finance the fiscal burden Japan is facing. One particular interpretation is that the government reduces transfers to deal with the economic impact of aging. In practice, however, reducing transfers significantly may not be politically feasible and the government may have to use distorting taxes such as the consumption tax and/or the labor income tax.

Before we consider the short run effects, it will be useful to describe the long run consequences of using distorting taxes. For this purpose, we define an effective tax rate as a function of $\tau_{c}$ and $\tau_{h}$ using equation (6):

$$
(1-\tau)=\left(1-\tau_{h}\right) /\left(1+\tau_{c}\right), \text { which implies that } \tau=\left(\tau_{c}+\tau_{h}\right) /\left(1+\tau_{c}\right) .
$$

As equation 19 indicates, both tax rates distort the static first order condition governing the labor/leisure decision. However, the amount of revenue raised by these taxes is not a function of $\tau$, but instead a function of $\tau_{c}$ and $\tau_{h}$ separately. In particular, the total tax revenue of the government in steady state is given by

$$
\bar{\tau}_{c} \bar{c}\left(\tau_{h}, \tau_{c}\right)+\bar{\tau}_{h} \bar{w}\left(\tau_{h}, \tau_{c}\right) \bar{h}\left(\tau_{h}, \tau_{c}\right)+\bar{\tau}_{k}\left(\bar{r}\left(\tau_{h}, \tau_{c}\right)-\delta\right) \bar{k}\left(\tau_{h}, \tau_{c}\right)+\bar{\tau}_{b}\left(1-\bar{q}\left(\tau_{h}, \tau_{c}\right)\right) \bar{b}\left(\tau_{h}, \tau_{c}\right)
$$

where a '-' over a variable indicates its steady state value. Note that steady state quantities such as consumption, hours worked, capital stock, bond holdings, as well as the wage rate, interest rate and the bond price depend on the particular configuration of $\tau_{h}$ and $\tau_{c}$. Throughout this section, we hold $\bar{\tau}_{k}$ constant at $35.57 \%$ and $\bar{\tau}_{b}$ at $20 \%$.

In Figure 14, we hold $\tau_{c}$ constant at $10 \%$ and plot total tax revenues as a function of the steady state labor income tax rate, $\bar{\tau}_{h}$. In addition, we normalize steady state revenues with respect to steady state government purchases and transfers, and plot revenues multiplied by $100 /(\bar{g}+\overline{t r})$.

Using our calibrated value for the Frisch elasticity of labor supply $\psi$ equal to 0.5 , one can see from Figure 14 that there exists no labor income tax rate in steady state that can raise needed steady state revenues. We show, however, that it is possible to raise sufficient revenues at the steady state with very high values for $\bar{\tau}_{h}$ at very low Frisch elasticities. We regard the extremely high labor income tax rate corresponding to the very low Frisch elasticities as being unreasonable parameterizations and therefore we do not pursue these cases further.

Instead, we consider increases in the consumption tax rate, perhaps in combination with increases in the labor income tax rate, that will raise the required revenue in the steady state. 


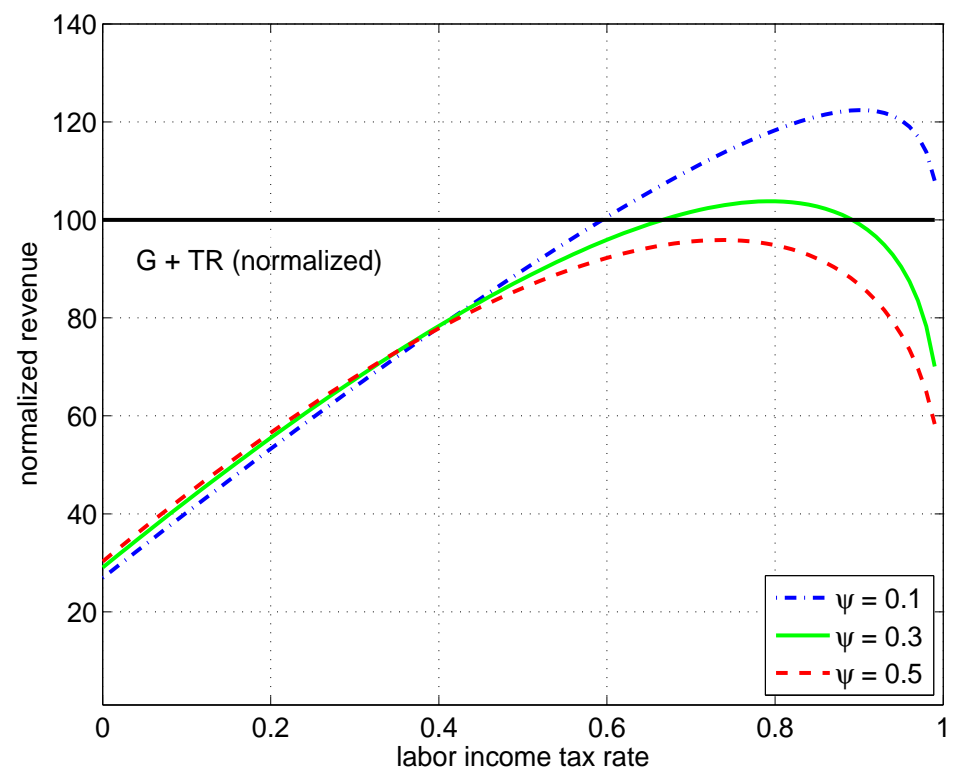

Figure 14: Labor Income Tax Rate and Steady State Tax Revenue

Figure 15 depicts the steady state relationship between the consumption tax rate and government revenues. Note that the value of the consumption tax rate needed to raise the required revenue is about $40 \%$ and not sensitive to the Frisch elasticity of labor supply. Still, a consumption tax of this magnitude would give pause to policymakers.

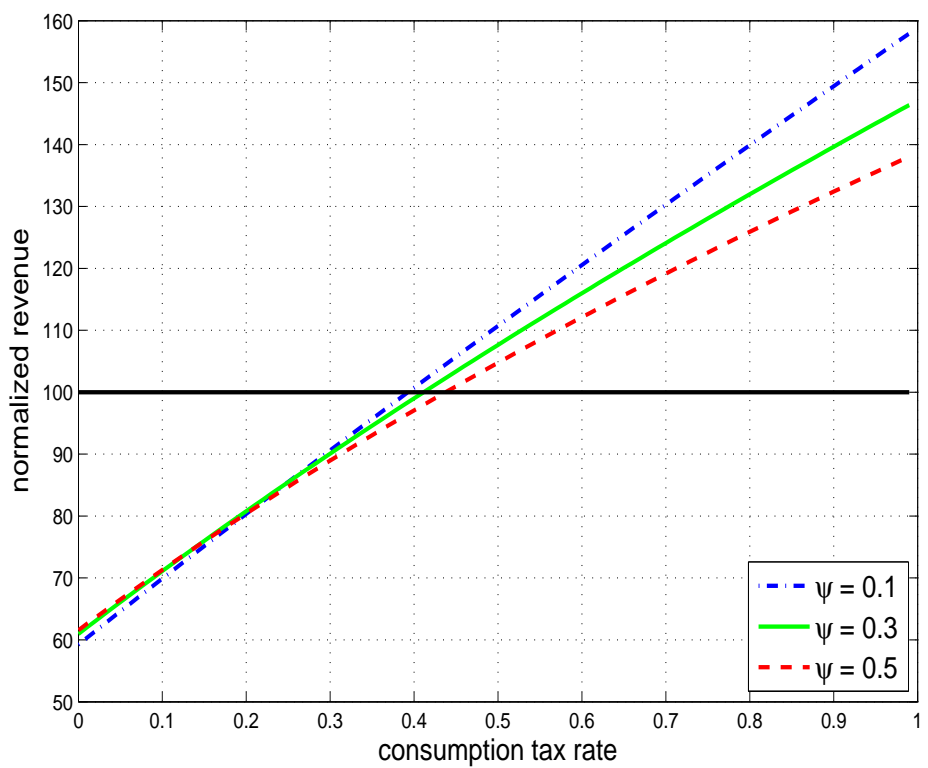

Figure 15: Consumption Tax Rate and Steady State Tax Revenue 
In Figure 16 we show combinations of $\bar{\tau}_{h}$ and $\bar{\tau}_{c}$ that raise the required steady state revenue. By increasing the labor income tax rate one can reduce the corresponding consumption tax rate until the steady state is on the wrong side of the "Laffer" curve. In addition, this figure shows that the tax distortion as defined above is minimized (i.e. the effective tax is minimized) by setting the labor income tax rate equal to zero and raising all of the revenue by a consumption tax equal to about $45 \%$. In other words, although consumption and labor income tax rates both raise the effective tax rate and distort the labor supply, for a given amount of revenue, it is better to use the consumption tax.

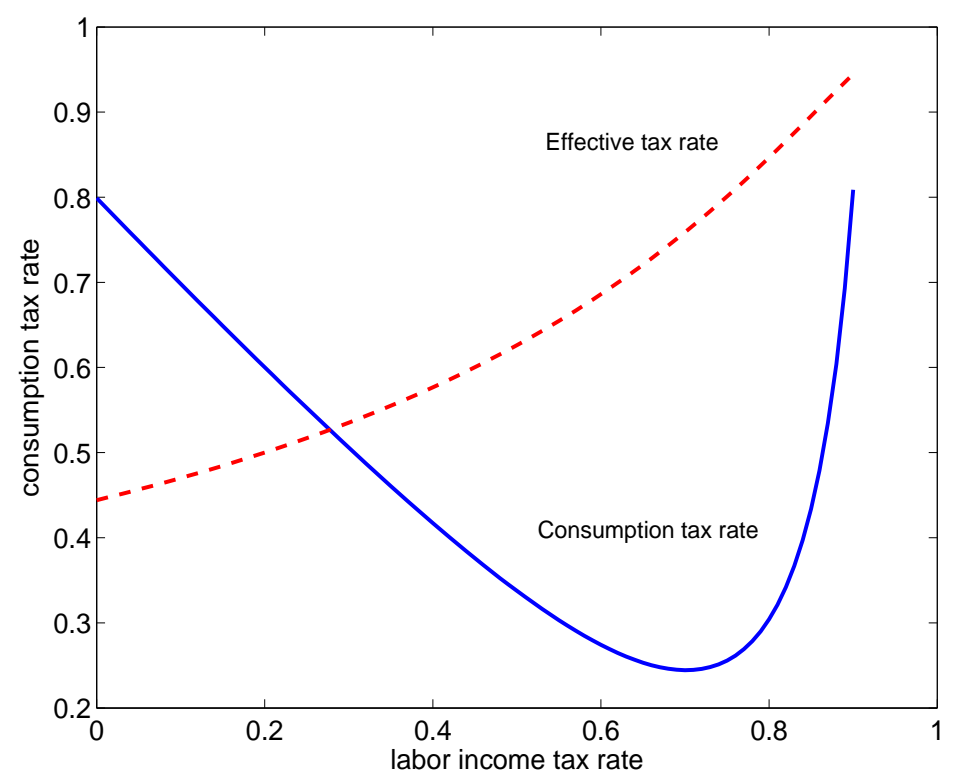

Figure 16: Steady State Iso-Revenue Curve

\subsection{Fiscal Policy Experiments}

Our benchmark exercise computes the additional revenue that must be raised to achieve fiscal balance in the steady state but does not incorporate the distortions that would be caused by higher tax rates. In this subsection, we compare the results from our benchmark experiment with ones that use the consumption tax and/or the labor income tax to achieve fiscal balance.

Before we can proceed, however, we need to fully specify the fiscal policies we consider. The specific fiscal policies considered are motivated by three considerations. First, we accept the likely political reality that there will be a tendency to put off any reform until it cannot be put off any further. This is why we use the debt to output trigger described below. Second, we focus on consumption and labor income tax rates because of their simplicity and because they do not involve the overwhelming distortions associated with increasing the capital income tax in this environment. Third, we also consider the possibility of broadening the tax base. We do this by reducing transfers by $8 \%$ of output. Recall that we added $8 \%$ of output to transfers as computed from Japanese 
data to account for the fact that we abstract from the exemptions and reductions in the Japanese tax code.

We assume that tax rates and transfers are equal to their benchmark values until the debt to output ratio hits the threshold level, $b_{\max }$. We denote these values by $\tau_{c, t}^{B}, \tau_{h, t}^{B}$, and $T R_{t}^{B}$. Once the threshold is hit, say at $t=T_{1}$, some or all of these fiscal parameters will change from their benchmark values. For example, if tax broadening is assumed, then $T R_{t}$ will equal $T R_{t}^{B}-0.08 Y_{t}$ for $t \geq T_{1}$.

In each of our experiments, one tax rate, either the consumption tax or the labor income tax, will be raised endogenously in the steady state to a level denoted by $\bar{\tau}_{c}$ or $\bar{\tau}_{h}$ to satisfy the government's steady state budget constraint. In addition, at the start of the transition $\left(t=T_{1}\right)$ this tax rate is raised by an amount $\pi$ over and above its steady state level to pay for the projected expenditures and pay off the accumulated debt so that the debt to output ratio converges to $\bar{b}$. In particular, $\pi$ is the smallest such value that facilitates convergence to the steady state.

This fiscal policy can be summarized as follows (where $x=c$ or $h$ and $t \geq 2010$ ):

$$
\tau_{x, t}= \begin{cases}\tau_{x, t}^{B} & \text { if } \left.t<T_{1} \text { (i.e. } B_{s} / Y_{s} \leq b_{\max } \text { for all } s \leq t\right) \\ \bar{\tau}_{x}+\pi & \text { if } T_{1} \leq t<T_{2}\left(\text { i.e. } B_{s} / Y_{s}>b_{\max } \text { for some } s \leq t \text { and } B_{t} / Y_{t}>\bar{b}\right) \\ \bar{\tau}_{x} & \text { if } t \geq T_{2}\left(\text { i.e. } B_{t} / Y_{t} \leq \bar{b}\right)\end{cases}
$$

where $T_{2}$ is the second trigger date which signals that the debt to output ratio has fallen to its steady state level $\bar{b}$.

Table 4 below summarizes the five experiments we consider in this section. The first two experiments use the consumption tax to achieve fiscal balance, while experiments 3-5 use the labor income tax. 
Table 4: Characterization of Fiscal Experiments

\begin{tabular}{|c|c|c|}
\hline Experiment 1 & $\begin{array}{l}\tau_{c, t}^{1} \\
\tau_{h, t}^{1} \\
T R_{t}^{1}\end{array}$ & $\begin{aligned} & = \begin{cases}\tau_{c, t}^{B} & t<T_{1}, \\
\bar{\tau}_{c}^{1}+\pi_{1} & T_{1} \leq t<T_{2}, \\
\bar{\tau}_{c}^{1} & t \geq T_{2} .\end{cases} \\
= & \tau_{h, t}^{B} \quad \text { for all } t, \\
= & T R_{t}^{B} \quad \text { for all } t,\end{aligned}$ \\
\hline Experiment 2 & $\begin{array}{l}\tau_{c, t}^{2} \\
\tau_{h, t}^{2} \\
T R_{t}^{2}\end{array}$ & $\begin{array}{l}= \begin{cases}\tau_{c, t}^{B} & t<T_{1}, \\
\bar{\tau}_{c}^{2}+\pi_{2} & T_{1} \leq t<T_{2}, \\
\bar{\tau}_{c}^{2} & t \geq T_{2} .\end{cases} \\
=\tau_{h, t}^{B} \text { for all } t, \\
= \begin{cases}T R_{t}^{B} & t<T_{1}, \\
T R_{t}-0.08 Y_{t} & t \geq T_{1},\end{cases} \end{array}$ \\
\hline Experiment 3 & $\tau_{h, t}^{3}$ & $\begin{array}{l}= \begin{cases}\tau_{c, t}^{B} & t<T_{1}, \\
\tau_{c, t}^{B}+0.3 & t \geq T_{1},\end{cases} \\
= \begin{cases}\tau_{h, t}^{B} & t<T_{1}, \\
\bar{\tau}_{h}^{3}+\pi_{3} & T_{1} \leq t<T_{2}, \\
\bar{\tau}_{h}^{B} & t \geq T_{2}\end{cases} \\
=T R_{t}^{B} \text { for all } t .\end{array}$ \\
\hline
\end{tabular}

$\begin{aligned} \text { Experiment } 4 \tau_{c, t}^{4} & = \begin{cases}\tau_{c, t}^{B} & t<T_{1}, \\ \tau_{c, t}^{B}+0.3 & t \geq T_{1},\end{cases} \\ \tau_{h, t}^{4} & = \begin{cases}\tau_{h, t}^{B} & t<T_{1}, \\ \bar{\tau}_{h}^{4}+\pi_{4} & T_{1} \leq t<T_{2}, \\ \bar{\tau}_{h}^{4} & t \geq T_{2},\end{cases} \\ T R_{t}^{4} & = \begin{cases}T R_{t}^{B} & t<T_{1}, \\ T R_{t}^{B}-0.08 Y_{t} & t \geq T_{1} .\end{cases} \end{aligned}$

\begin{aligned} \hline Experiment $5 \tau_{c, t}^{5} & = \begin{cases}\tau_{c, t}^{B} & t<T_{1}, \\ \tau_{c, t}^{B}+0.05 & t \geq T_{1},\end{cases} \\ \tau_{h, t}^{5} & = \begin{cases}\tau_{h, t}^{B} & t<T_{1}, \\ \bar{\tau}_{h}^{5}+\pi_{5} & T_{1} \leq t<T_{2}, \\ \bar{\tau}_{h}^{5} & t \geq T_{2},\end{cases} \\ T R_{t}^{5} & = \begin{cases}T R_{t}^{B} & t<T_{1}, \\ T R_{t}^{B}-0.08 Y_{t} & t \geq T_{1} .\end{cases} \end{aligned}$




\subsubsection{Experiments 1 and 2 (Consumption Tax)}

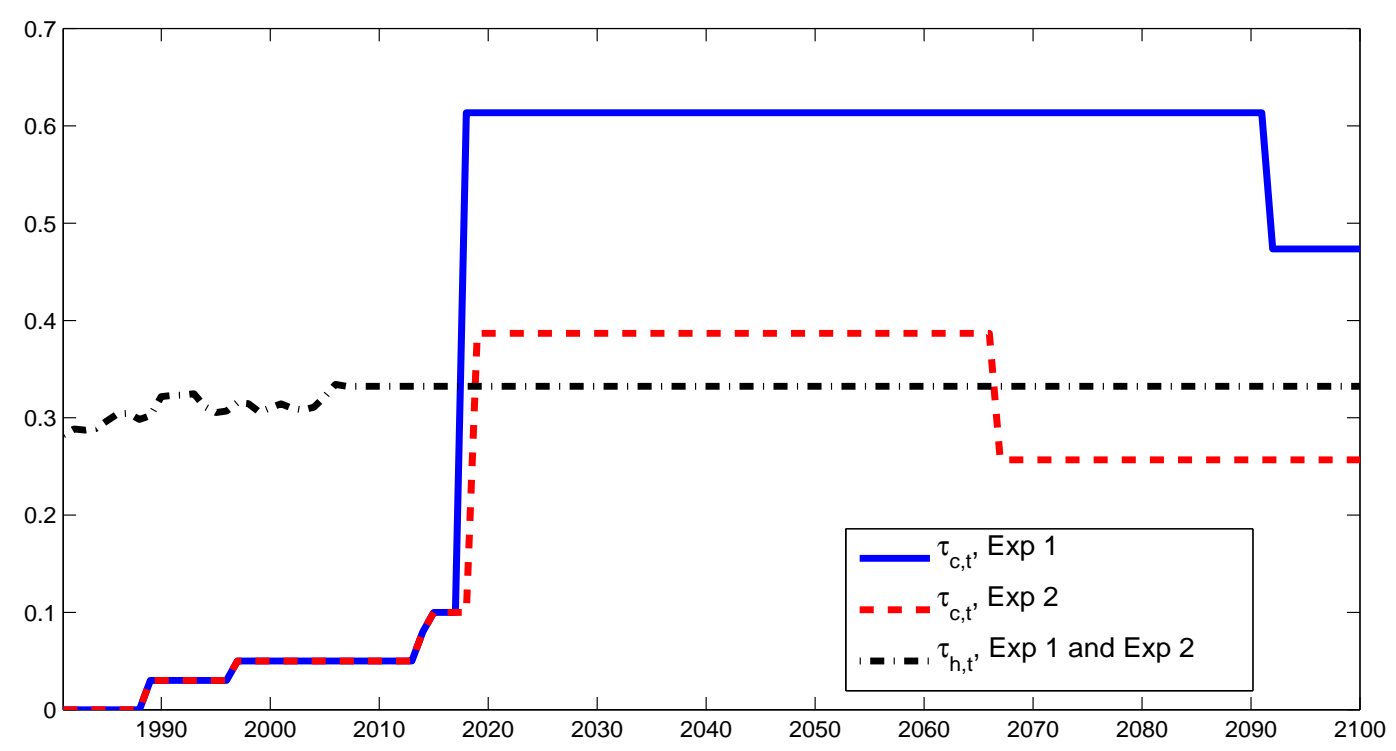

Figure 17: Consumption Tax Experiments

Figure 17 shows the projected time path of $\tau_{c, t}$ in experiments 1 and 2 when this tax rate is used to finance the projected increases in expenditures and to reduce the debt to output (eventually) to 60\%. The labor income tax rate in these experiments is assumed to follow the same path as in the benchmark case.

The difference between experiments 1 and 2 is the presence of tax broadening in experiment 2 and its absence in experiment 1. The solid line depicts the time path of the consumption tax in experiment 1 when it is the only fiscal policy instrument used to achieve fiscal balance. In this case, there is a very sharp increase in the consumption tax in $T_{1}=2018$ from $10 \%$ to $61.4 \%$. Eventually, at $T_{2}$, the consumption tax rate reaches its steady state value of $\bar{\tau}_{c}^{1}=47.4 \%$.

When we assume in experiment 2 that the government broadens the tax base by $8 \%$ of output, the consumption tax rises from $10 \%$ to $38.7 \%$ at $T_{1}=2019$. It then converges to its steady state value of $\bar{\tau}_{c}^{2}=25.7 \%$, more quickly than before. The significant reduction in transfers allows the government to contain the increase in the consumption tax needed to pay for the projected increases and at the same time bring the debt to output ratio down to the prescribed value of $60 \%$ much sooner.

\subsubsection{Experiments 3-5 (Labor Income Tax)}

As Figure 14 shows, it is impossible to raise sufficient revenue to cover the projected expenditures at the steady state when the government relies exclusively on increasing the 
labor income tax. In Figure 18 we consider additional fiscal policies that complement the increase in the labor income tax so that sufficient revenues are raised.

In our first two labor income tax experiments, denoted experiments 3 and 4 , when the debt to output ratio reaches the first trigger value of $250 \%$ in $T_{1}$, the consumption tax rate is increased exogenously from $10 \%$ to $40 \% .^{12}$

In experiment 3 , the labor income tax rate rises to $56.7 \%$ in $T_{1}=2020$, eventually falling to its steady state value of $\bar{\tau}_{h}^{3}=41.7 \%$. In experiment 4 , in addition to the increase in the consumption tax to $40 \%$, we allow for tax base broadening, as in experiment 2 in the consumption tax case. Now, the trigger is activated in $T_{1}=2019$ at which point the labor income tax rate drops slightly from $33.2 \%$ to $33.1 \%$, eventually falling to its steady state level of $\bar{\tau}_{h}^{4}=20.1 \%$.

While a very large permanent increase in the consumption tax is required when there is no tax base broadening, clearly no such increase is needed in experiment 4 . Hence, in experiment 5, we increase the consumption tax to just $15 \%$ (five percentage points above its benchmark value) at date $T_{1}$ while also allowing for tax base broadening. ${ }^{13}$ This turns out to happen in $T_{1}=2023$, at which time the labor income tax rate is raised to $63.2 \%$, falling eventually to its steady state level of $\bar{\tau}_{h}^{5}=46.2 \%$.

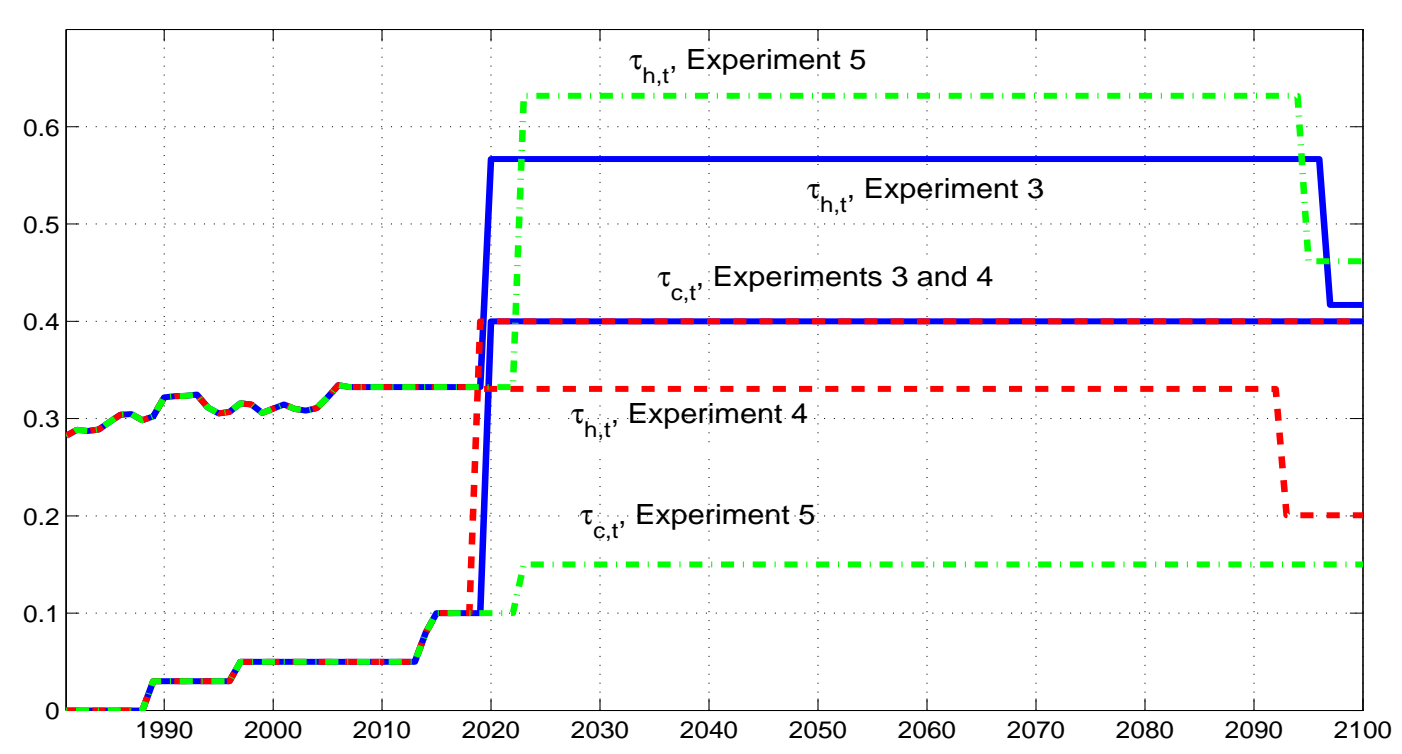

Figure 18: Labor Income Tax Experiments

These experiments show that without tax base broadening very large increases in either the consumption tax or the labor income tax (or both) is required. Such fiscal

\footnotetext{
${ }^{12}$ Our numerical solution method (shooting algorithm) was unable to find an equilibrium in experiment 3 unless the consumption tax rate were increased to this level.

${ }^{13}$ Again, the five percentage point increase in the consumption tax rate was required to compute an equilibrium.
} 
policies are not likely to be adopted. Unless one is willing to accept extremely high labor income tax rates, Japan needs to find ways to broaden its tax base and to increase its consumption tax rate to $40 \%$ for a few decades.

\subsubsection{Comparing the Benchmark with Alternative Policies}

Below, we compare the equilibrium transition paths of key macroeconomic indicators under the benchmark fiscal policy and two alternative fiscal policies associated with experiments 2 and 5 in which required the tax revenue is reduced by $8 \%$ of output. Recall that in experiment 2, the first trigger of $250 \%$ debt to output ratio is hit in 2019 and therefore the consumption tax is increased from $10 \%$ to $38.7 \%$, eventually declining to its steady state level of $25.7 \%$. In experiment 5, the trigger is activated in 2023 when the consumption tax rate is raised to $15 \%$ and the labor income tax rate is increased to $63.2 \%$, eventually falling to its steady state level of $46.2 \%$.

Before we begin the description of the effects of fiscal responses, it will be useful to discuss the distortions created by the consumption and the labor income tax rates. In our environment, the consumption tax distorts the saving decision when the consumption tax rate changes over time. In particular, when the consumption tax rate is expected to increase at some future date, this makes consumption today relatively cheaper compared to consumption in the future. As a result, there is an intertemporal distortion that reduces saving and raises consumption today. When the consumption tax does increase, then there is a drop in consumption and a rise in investment.

As discussed in section 4.2, both tax rates appear in the first order condition for labor and distort labor supply. When one conditions the increases in the consumption and labor income tax rates on raising the same fixed revenue, then the consumption tax rate produces a much smaller distortion in labor supply. 


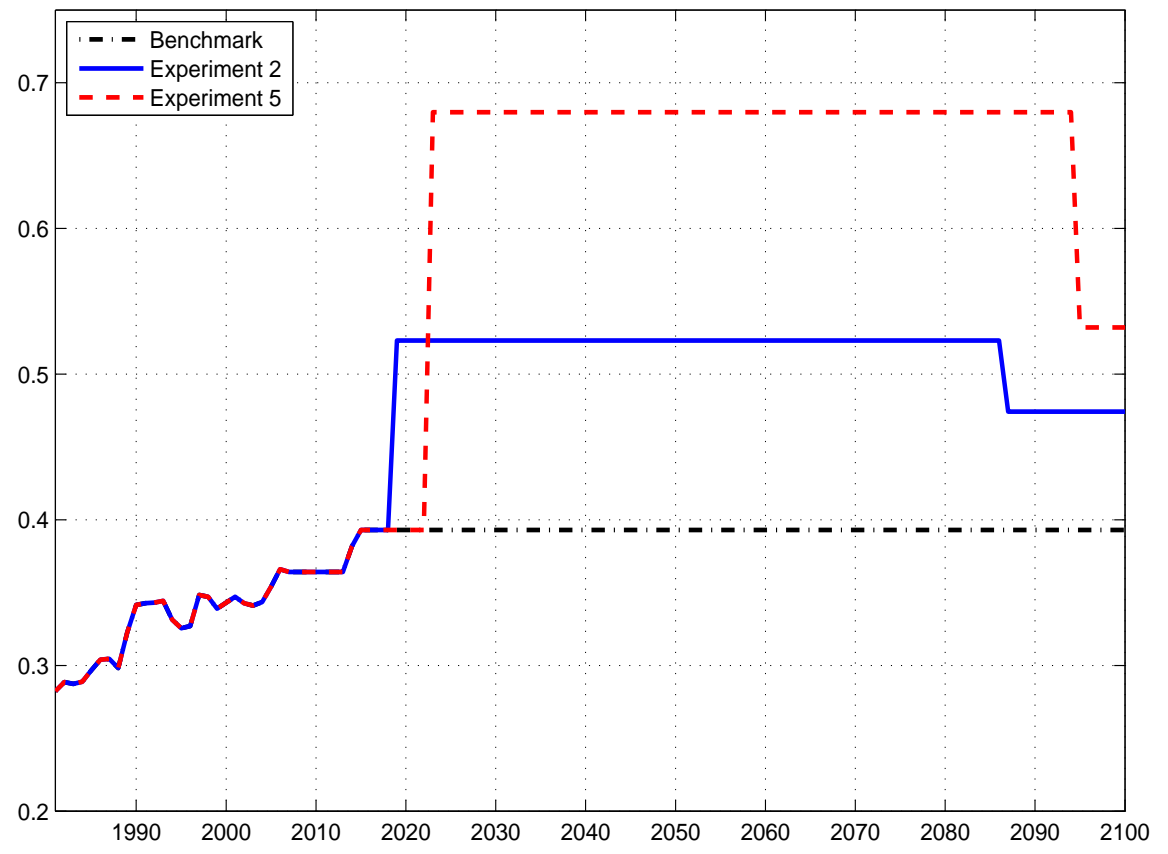

Figure 19: Effective Tax Rate

In Figure 19, we show the effective tax rate $\tau$ (defined in equation 19) across three selected experiments all of which use identical paths of government purchases and transfer payments. The figure shows that the resulting increase in the effective tax rate is much higher when the labor tax is the primary tool used to retire Japan's debt than if the consumption tax is used instead. Because the labor income tax is more distorting in this environment, hours worked and output are more depressed when the labor income tax is the primary fiscal instrument employed.

In Figure 20, we show the transition paths of consumption and investment, where everything is expressed relative to the benchmark values in 2010 . 

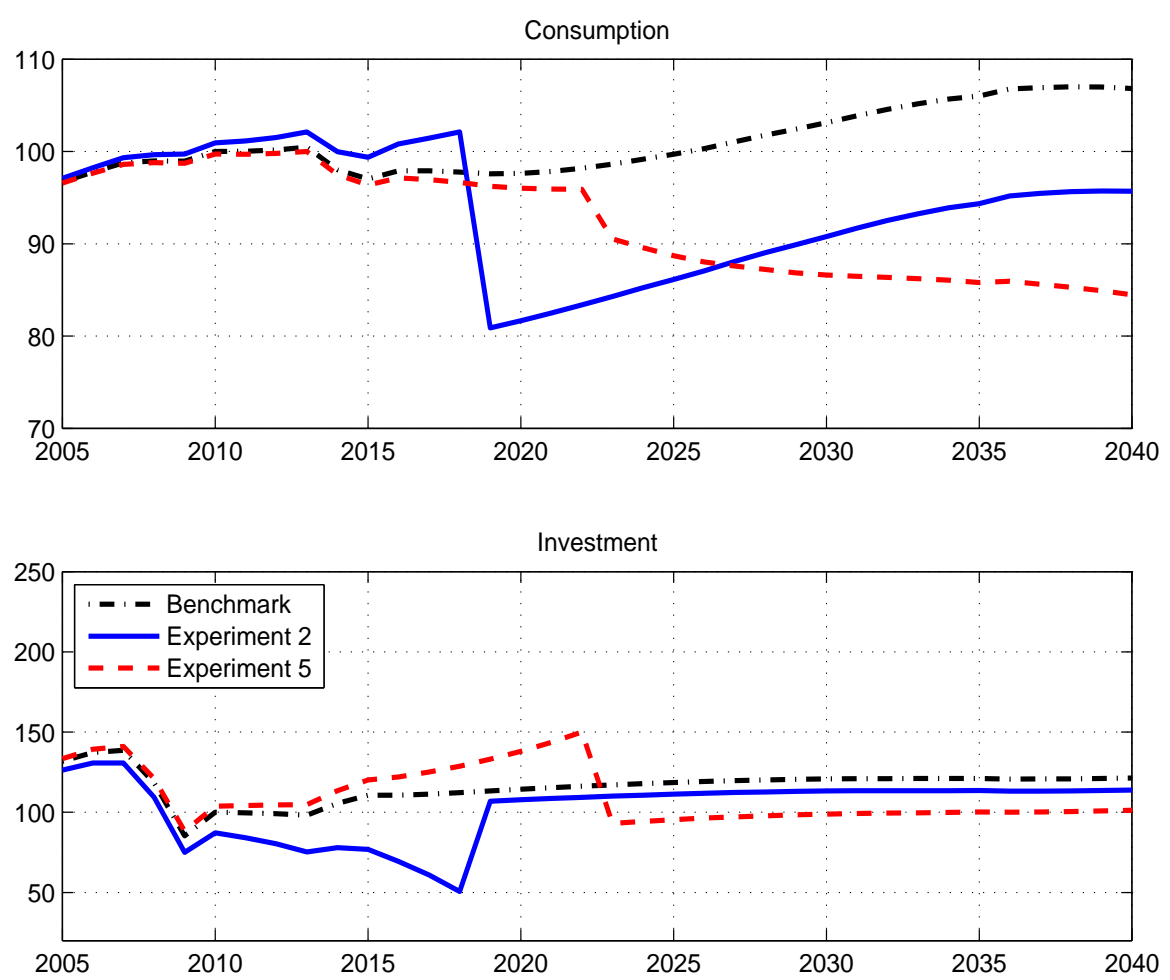

Figure 20: Consumption and Investment

As the top frame in Figure 20 shows, there is a consumption boom in experiment 2 which starts even before 2010 in anticipation of the huge increase in the consumption tax in 2019. When the consumption tax increases in 2019, there is a very sharp decline in consumption. The mirror image of this consumption path can be seen in the bottom frame of Figure 20 as investment drops significantly for several years until the consumption tax is raised in 2019 when there is a huge jump in investment.

The bottom frame in Figure 20 shows that in experiment 5 there is a large increase in investment prior to 2023 when the labor income tax rate is raised significantly. At this date, there is a very sharp decline in investment as well as consumption. 

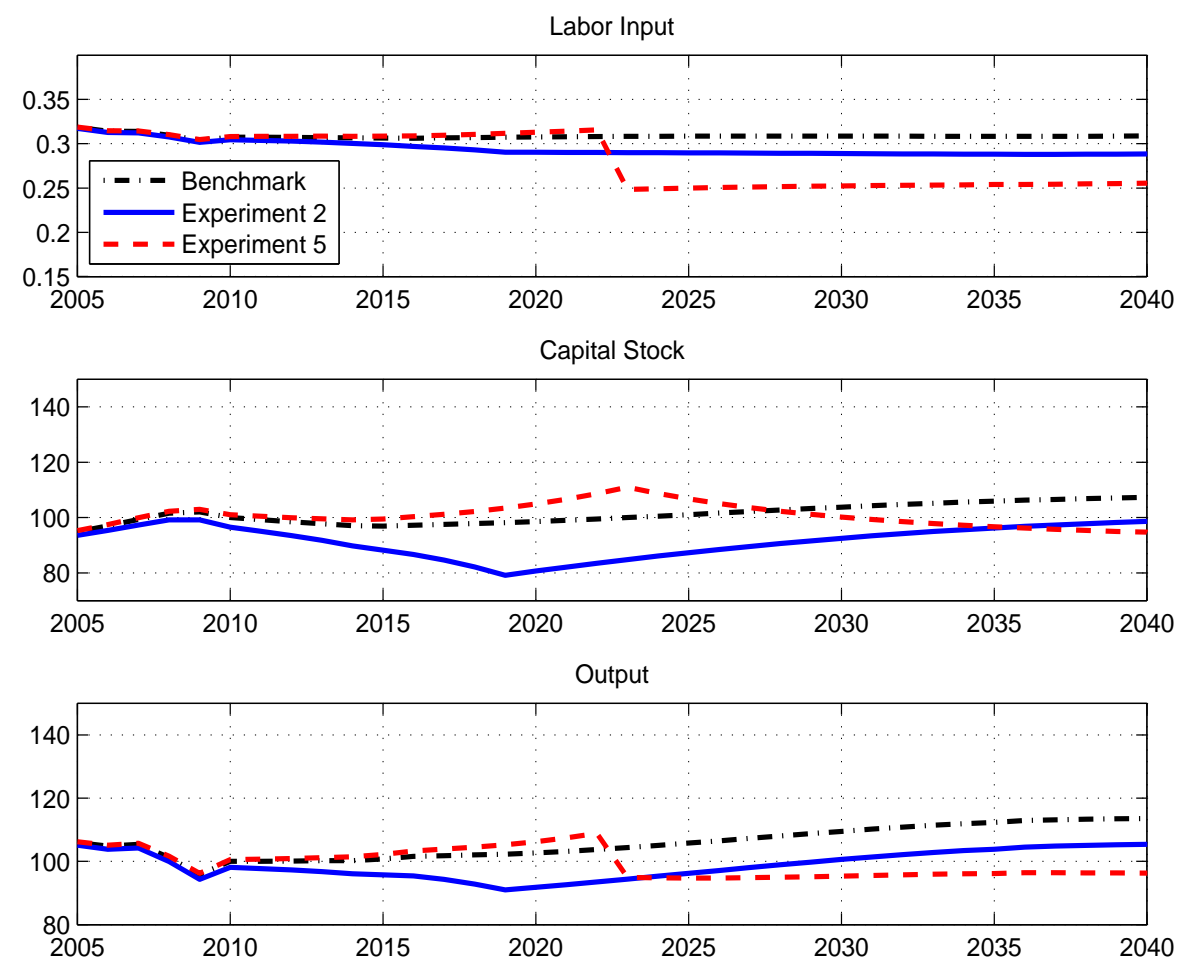

Figure 21: Labor, Capital, and Output

Figure 21 depicts the responses of labor, capital and output in the selected experiments. In the top frame of Figure 21, there is a sharp decline in hours worked, and as a result, in output, in response to the large increase in the labor income tax rate of experiment 5. In experiment 2 , however, the distortion on labor supply is much smaller and spread over time. In the second and third frames of Figure 21 the effects of changes in hours worked and investment are reflected in changes in the capital stock and output.

Figure 22 shows the transition paths for debt to output ratios under the same three scenarios. 


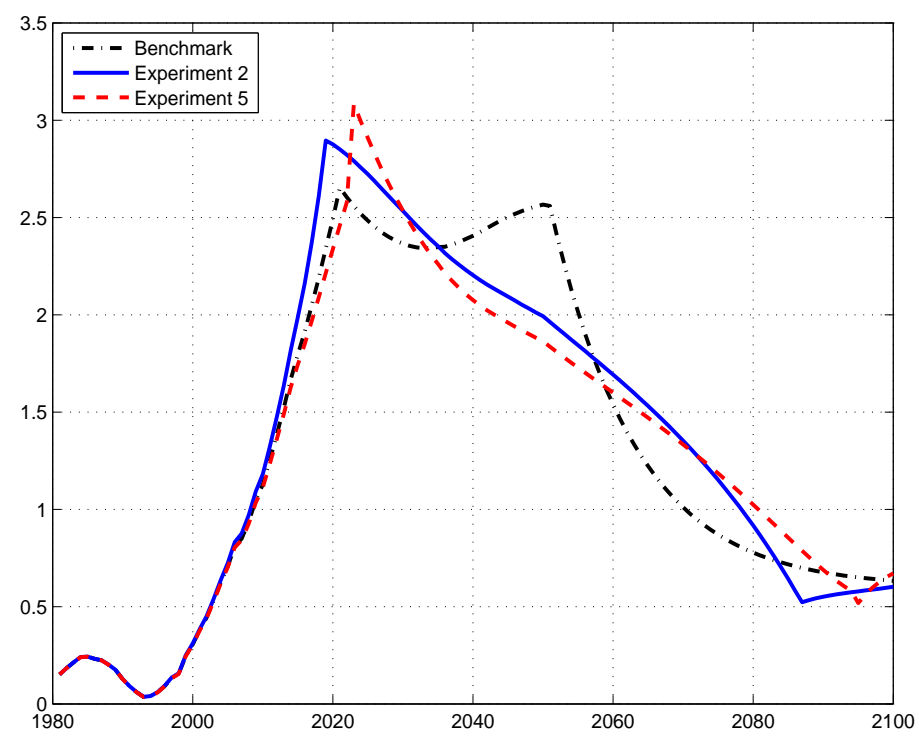

Figure 22: Debt to Output Ratios

\subsection{Sensitivity Analysis}

Here we examine the sensitivity of our results to the parameter $\psi$, which is the intertemporal elasticity of substitution of labor supply, in this case also the Frisch elasticity of labor supply, and our measure of population. Note that in our benchmark experiment, the consumption tax rate after 2010 follows the expected path according to current law in Japan, namely, the consumption tax rate is projected to rise from $5 \%$ to $8 \%$ in 2014 and to $10 \%$ in 2015 . The labor income tax rate is equal to $33.2 \%$ for 2007 and beyond. In our experiments, one or both these tax rates change according to the fiscal sustainability rule we impose on the government.

\subsubsection{Frisch Elasticity and Economic Responses}

To explore the role played by the Frisch elasticity, we consider a lower value $\psi=0.25$ and compare the economic responses to those from the benchmark value of $\psi=0.5$. Table 5 describes our findings. 
Table 5: Frisch Elasticity and Equilibrium Tax Rates

\begin{tabular}{lrrrr}
\hline \hline & \multicolumn{3}{c}{ Experiment 2} & \multicolumn{2}{c}{ Experiment 5} \\
\cline { 2 - 5 }$T_{1}$ & $\psi=0.5$ & $\psi=0.25$ & $\psi=0.5$ & $\psi=0.25$ \\
$\tau_{c, T_{1}}$ & $40.0 \%$ & $38.7 \%$ & $(*)$ & 2022 \\
$\tau_{h, T_{1}}$ & $(*)$ & $(*)$ & $63.2 \%$ & $54.5 \%$ \\
$\tau_{T_{1}}$ & $52.3 \%$ & $51.9 \%$ & $68.0 \%$ & $60.4 \%$ \\
$T_{2}$ & 2087 & 2067 & 2095 & 2096 \\
$\tau_{c, T_{2}}$ & $27.0 \%$ & $25.7 \%$ & $(*)$ & $\left({ }^{*}\right)$ \\
$\tau_{h, T_{2}}$ & $(*)$ & $(*)$ & $46.2 \%$ & $43.5 \%$ \\
$\tau_{T_{2}}$ & $47.4 \%$ & $46.9 \%$ & $53.2 \%$ & $50.8 \%$ \\
\hline \hline$T_{1}:$ Date when $B / Y$ reaches $250 \%$ & \\
$T_{2}:$ Date when $B / Y$ is less than or equal to $60 \%$. \\
$\tau_{c, i}:$ Consumption tax rate at date $i$ \\
$\tau_{h, i}:$ Labor income tax rate at date $i$ \\
$\tau_{i}=\left(\tau_{c, i}+\tau_{h, i}\right) /\left(1+\tau_{c, i}\right):$ Effective tax rate at date $i$
\end{tabular}

$\left(^{*}\right)$ indicates values equal to those in the benchmark case.

In Table 5 we show the first year that our fiscal sustainability rule is triggered, which occurs when the debt to output ratio exceeds $250 \%$, and the new levels of relevant tax rates. In particular, we show results from experiments 2 and 5 , both of which are described in the previous subsection. Columns labeled $\psi=0.5$ report the findings that are also shown in Figures 17 and 18.

In experiment 2, using the smaller Frisch elasticity results in a relatively small change. With a smaller distortion in labor supply, a slightly smaller consumption tax during the transition can now provide fiscal sustainability. The only notable difference is the shortened length of the transition of the consumption tax rate to its steady state value of $46.9 \%$. The transition is now 20 periods shorter than with $\psi=0.5$.

In experiment 5 , the length of transition is about the same, but the labor income tax rate during the transition is now lower at $54.5 \%$ relative to $63.2 \%$. The smaller Frisch elasticity results in a smaller distortion in labor supply and therefore a tax rate not as high as that required when $\psi=0.5$.

\subsubsection{Working Age Population versus Total Population}

In this paper we have calculated 'per capita' variables by using the working age population. This assumption may imply a relatively small consumption tax base as we abstract from the people above the age of 69 who also pay this tax. Hence, in this subsection we use total population in Japan as an alternative measure of population to examine if this larger tax base will change our results. 
Table 6 presents the key findings from the two consumption tax experiments in Figure 17 (experiments 1 and 2) and the corresponding experiments using total population instead of working age population.

Table 6: Working Age vs Total Population

\begin{tabular}{lrrrr}
\hline \hline & \multicolumn{2}{c}{ Experiment 1 } & \multicolumn{2}{c}{ Experiment 2 } \\
\cline { 2 - 5 } Population & Age 20-69 & Total & Age 20-69 & Total \\
$T_{1}$ & 2018 & 2019 & 2019 & 2021 \\
$\tau_{c, T_{1}}$ & $61.4 \%$ & $57.0 \%$ & $40.0 \%$ & $36.7 \%$ \\
$\tau_{T_{1}}$ & $58.6 \%$ & $57.5 \%$ & $52.3 \%$ & $51.2 \%$ \\
$T_{2}$ & 2092 & 2088 & 2087 & 2098 \\
$\tau_{c, T_{2}}$ & $47.4 \%$ & $46.0 \%$ & $27.0 \%$ & $25.7 \%$ \\
$\tau_{T_{2}}$ & $54.7 \%$ & $54.3 \%$ & $47.4 \%$ & $46.9 \%$ \\
\hline \hline
\end{tabular}

$\tau_{T_{2}}$ : Date when $B / Y$ reaches $250 \%$
$T_{2}:$ Date when $B / Y$ is less than or equal to $60 \%$.
$\tau_{c, i}:$ Consumption tax rate at date $i$
$\tau_{i}=\left(\tau_{c, i}+\tau_{h, i}\right) /\left(1+\tau_{c, i}\right):$ Effective tax rate at date $i$

Indeed, as Table 6 shows, using a population measure that includes retirees makes a difference. In particular, the larger population measure produces a smaller equilibrium consumption tax rate during the transition. The difference is about four percentage points in both experiments, although this difference nearly vanishes in steady state.

\section{Conclusions}

Japan is aging rapidly. The ratio of the number of Japanese over the age of 64 to those between 20 and 64 is projected to increase from $39 \%$ in 2010 to above $91 \%$ in 2070 . This dramatic shift in the share of elderly in the society is expected to raise public retirement and health expenditures significantly. Indeed, the ratio of these aging-related expenditures to output is projected to rise an additional 7 percentage points. In addition, past spending decisions have already caused the net debt to output ratio to soar above $110 \%$ by 2010 .

In this paper we build a neoclassical growth model to measure the size of the fiscal response needed to restore fiscal balance in Japan. In our model, both consumption and labor income taxes distort labor supply. However, for a given amount of revenue, the consumption tax is less distorting than the labor income tax.

Our main result is that fiscal sustainability requires a large adjustment in tax revenues, in the range of 30-40\% of aggregate consumption if we abstract from distortions. Adjusting the consumption or labor income tax rate to achieve this, however, requires that taxes be set to unprecedentedly high levels-tax rates of $40-60 \%$. The lower end of this range is made possible if revenue equal to $8 \%$ of output can be raised through broadening the tax base. 
The dismal nature of these findings is motivation for research that explores policy measures that will allow some of the fiscal adjustment to come from sources other than higher taxes. These may include reducing expenditures via reforms of public pensions and health expenditures, a new approach to immigration, family policies to raise fertility and to increase female labor force participation, and microeconomic reforms to incentivize higher rates of innovation and growth. 


\section{References}

Chen, K., A. İmrohoroğlu, and S. İmrohoroğlu (2006). The Japanese saving rate. American Economic Review 96(5), 1850-1858.

Chetty, R., A. Guren, D. Manoli, and A. W. Broda (2012). Does indivisible labor explain the the difference between micro and macro elasticities? a meta-analysis of extensive margin elasticities. In J. P. Daron Acemoglu and M. Woodford (Eds.), NBER Macroeconomics Annual, pp. 1-56. Massachusetts: The University of Chicago Press.

Doi, T., T. Hoshi, and T. Okimoto (2011). Japanese government debt and sustainability of fiscal policy. Journal of the Japanese and International Economies 25(4), 414433.

Fukawa, T. and I. Sato (2009). Projection of pension, health and long-term care expenditures in japan through macro simulation. The Japanese Journal of Social Security Policy 8(1), 33-42.

Gunji, H. and K. Miyazaki (2011). Estimates of average marginal tax rates on factor incomes in japan. Journal of the Japanese and International Economies 25(2), 81106.

Hayashi, F. and E. C. Prescott (2002). The 1990s in japan: A lost decade. Review of Economic Dynamics 5(1), 206-235.

Hoshi, T. and T. Ito (2012). Defying gravity: How long will Japanese government bond prices remain high? NBER Working Paper No. 18287.

İmrohoroğlu, S., S. Kitao, and T. Yamada (2013). Achieving fiscal balance in Japan. Working Paper.

İmrohoroğlu, S. and N. Sudo (2011a). Productivity and fiscal policy in japan: Short term forecasts from the standard growth model. Monetary and Economic Studies, Institute for Monetary and Economic Studies, Bank of Japan 29(November), 73106.

İmrohoroğlu, S. and N. Sudo (2011b). Will a growth miracle reduce debt in japan? The Economic Review (Keizai Kenkyuu, Institute of Economic Research, Hitotsubashi University) 62(1), 44-56.

Keen, M., M. Pradhan, K. Kang, and R. de Mooij (2011). Raising the consumption tax in japan: Why, when, how? IMF Discussin Note No. 11/13.

Sakuragawa, M. and K. Hosono (2010). Fiscal sustainability of japan: A dynamic stochastic general equilibrium approach. The Japanese Economic Review 61(4), $517-537$.

Sato, I. and H. Kato (2007). Financial projection of the Japanese social security through macro simulation. The Japanese Journal of Social Security Policy 6(2), 185-198. 